\title{
Assessment of Cloudsat Reflectivity Measurements and Ice Cloud Properties Using Ground-Based and Airborne Cloud Radar Observations
}

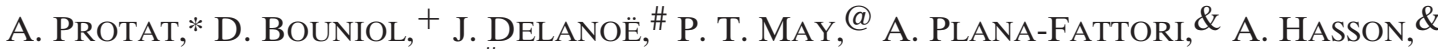 \\ E. O'CONNOR, ${ }^{\#}$ U. GÖRSDORF,** AND A. J. HEYMSFIELD ${ }^{++}$ \\ * The Centre for Australian Weather and Climate Research, Melbourne, Victoria, Australia, and Centre d'étude \\ des Environnements Terrestre et Planétaires, Vélizy, France \\ + Centre National de Recherches Météorologiques, Groupe d'étude de l'Atmosphère Météorologique, Toulouse, France \\ \# University of Reading, Reading, United Kingdom \\ @ The Centre for Australian Weather and Climate Research, Melbourne, Victoria, Australia \\ \& Centre d'étude des Environnements Terrestre et Planétaires, Vélizy, France \\ ** Deutscher Wetterdienst, Meteorologisches Observatorium, Lindenberg, Germany \\ ${ }^{++}$National Center for Atmospheric Research, Boulder, Colorado
}

(Manuscript received 17 October 2008, in final form 31 March 2009)

\begin{abstract}
A quantitative assessment of Cloudsat reflectivities and basic ice cloud properties (cloud base, top, and thickness) is conducted in the present study from both airborne and ground-based observations. Airborne observations allow direct comparisons on a limited number of ocean backscatter and cloud samples, whereas the ground-based observations allow statistical comparisons on much longer time series but with some additional assumptions. Direct comparisons of the ocean backscatter and ice cloud reflectivities measured by an airborne cloud radar and Cloudsat during two field experiments indicate that, on average, Cloudsat measures ocean backscatter $0.4 \mathrm{~dB}$ higher and ice cloud reflectivities $1 \mathrm{~dB}$ higher than the airborne cloud radar. Five ground-based sites have also been used for a statistical evaluation of the Cloudsat reflectivities and basic cloud properties. From these comparisons, it is found that the weighted-mean difference $Z_{\text {Cloudsat }}-Z_{\text {Ground }}$ ranges from -0.4 to $+0.3 \mathrm{~dB}$ when a \pm 1 -h time lag around the Cloudsat overpass is considered. Given the fact that the airborne and ground-based radar calibration accuracy is about $1 \mathrm{~dB}$, it is concluded that the reflectivities of the spaceborne, airborne, and ground-based radars agree within the expected calibration uncertainties of the airborne and ground-based radars. This result shows that the Cloudsat radar does achieve the claimed sensitivity of around $-29 \mathrm{dBZ}$. Finally, an evaluation of the tropical "convective ice" profiles measured by Cloudsat has been carried out over the tropical site in Darwin, Australia. It is shown that these profiles can be used statistically down to approximately 9-km height (or $4 \mathrm{~km}$ above the melting layer) without attenuation and multiple scattering corrections over Darwin. It is difficult to estimate if this result is applicable to all types of deep convective storms in the tropics. However, this first study suggests that the Cloudsat profiles in convective ice need to be corrected for attenuation by supercooled liquid water and ice aggregates/graupel particles and multiple scattering prior to their quantitative use.
\end{abstract}

\section{Introduction}

A crucial factor to improve our ability to forecast future climate change and short-range weather is a better representation of convection and clouds in large-scale models. This requires a better understanding of the statistical properties of clouds and deep convective storms,

Corresponding author address: Alain Protat, Centre for Australian Weather and Climate Research (CAWCR), 700 Collins Street, Docklands, Melbourne, VIC 3008, Australia.

E-mail: a.protat@bom.gov.au as well as the variability of these properties as a function of different temporal and spatial scales or physical parameters describing the large-scale environment (e.g., Protat et al. 2009). The A-Train mission (Stephens et al. 2002), which is a constellation of six satellites dedicated to the observation of clouds, precipitation, and aerosols from space, represents an unprecedented and unique opportunity to address this broad objective both at regional and global scales. Because this mission is the very first of its kind, an extensive verification of the measurements and standard products is required prior to using these for quantitative studies. The prelaunch calibration 
of Cloudsat, in-flight calibration, and stability over the period of operations has been very recently reported in Tanelli et al. (2008). This in-flight calibration relies on monthly comparisons of ocean backscatter measured at $10^{\circ}$ incidence off-nadir using dedicated Cloudsat maneuvers and the corresponding ocean backscatter predicted by different theoretical models. A complementary approach to that adopted in Tanelli et al. (2008) is to compare Cloudsat observations with other radar measurements, either collocated or in a statistical sense. For this reason many international and national experiments have been conducted following the launch of two of the A-Train satellites, Cloudsat (95-GHz cloud radar) and Cloud-Aerosol Lidar and Infrared Pathfinder Satellite Observation (CALIPSO), including dedicated A-Train underflights with airborne passive and active remote sensing and in situ instruments; for example, the CALIPSOCloudsat Validation Experiment (CCVEX; available online at http://airbornescience.nasa.gov/media/) in Florida in July-August 2006, the Canadian Cloudsat/CALIPSO Validation Project (C3VP; available online at http:// www.c3vp.org) in Canada from November 2006 to March 2007, the African Monsoon Multidisciplinary Analyses (AMMA) over West Africa in June-September 2006, and the French-German Cirrus Clouds Experiment-2 (CIRCLE-2; available online at http://www.pa.op.dlr.de/ pazi-falcon/circle2/) over Western Europe in May 2007. Among the different validation campaigns, our team has been involved with airborne radar, lidar, and in situ microphysical measurements during AMMA (Redelsperger et al. 2006), CIRCLE-2, and very recently during a third campaign in the Arctic. The main advantage of the airborne observations is that they allow direct comparisons with the spaceborne measurements, because they sample the cloud with approximately the same geometry as the spaceborne instrument (from the top down) and with a good temporal coincidence.

Ground-based continuous observations such as those conducted in the framework of the U.S. Department of Energy Atmospheric Radiation Measurement Program (ARM; Stokes and Schwartz 1994) and the European Union Cloudnet program (Illingworth et al. 2007) are also relevant for spaceborne instrumentation assessment. The main advantage of this is that long-term and multisensor ground-based observations (radars, lidars, radiometers, and in situ sensors) are readily available over selected sites at midlatitudes and in the tropics. From the combination of these instruments put together at those sites, the morphological, microphysical, radiative, and dynamical properties of clouds are routinely and accurately retrieved. The accuracy of these cloud properties retrieved from the ground-based stations provides a reference for the evaluation of the spaceborne products.
However, it generally does not allow for direct comparisons but requires statistical assumptions. The geometry of observations is also different, which introduces additional sources of discrepancy, including that observations are not attenuated the same way into the cloud.

In the present paper, we exploit the specific advantages of airborne and ground-based radar observations by conducting both statistical and direct assessments of the Cloudsat 95-GHz Cloud Profiling Radar (CPR) observations. The paper is organized as follows: the observations and methodology adopted are described in section 2. In section 3, the Cloudsat reflectivity measurements and macrophysical properties of ice clouds are assessed using direct comparisons with airborne observations. Statistical comparisons with ground-based observations are analyzed in section 4. An assessment of the reflectivity profiles measured by Cloudsat in the ice part of convective systems is also conducted in section 5 by using unattenuated ground-based radar observations and an estimate of the mean attenuation plus the multiple scattering profile is worked out. Conclusions and perspectives of this work are given in section 6 .

\section{Observations and methodology}

The assessment of Cloudsat ice cloud measurements and products is conducted in the present study from both airborne and ground-based observations. The Cloudsat data used in the present paper are from the fourth release (R04) of the Cloudsat radar reflectivities given in the so-called 2B-GEOPROF product. A review of the performance, external calibration, and processing has been published during the review process of the present paper (Tanelli et al. 2008). The in-flight calibration of Cloudsat relies on comparisons of ocean backscatter measured at $10^{\circ}$ incidence off nadir using dedicated monthly Cloudsat calibration maneuvers and predicted by different theoretical models. It has been clearly shown in Tanelli et al. (2008) that the Cloudsat-derived ocean backscatter is in very good agreement with the Cox and Munk (1954) model modified following Li et al. (2005) and with the $\mathrm{Wu}$ (1990) model. The absolute calibration of Cloudsat is derived from these comparisons. The approach adopted in the present paper is very complementary, because it consists of comparing Cloudsat observations to other radars, either statistically or by using direct comparisons. The rationale for using both airborne and ground-based observations is that they provide very different ways of evaluating Cloudsat and using different assumptions. Airborne observations allow for direct comparisons on a limited number of collocated ground return or cloud samples, whereas the groundbased observations allow for statistical comparisons using 
TABLE 1. List of Cloudsat validation flights with RASTA on board the Falcon 20 during AMMA and CIRCLE-2. Here, Ci indicates cirrus.

\begin{tabular}{|c|c|c|c|c|}
\hline \multirow[b]{2}{*}{ Date } & \multicolumn{2}{|c|}{ Measurement period } & \multirow[b]{2}{*}{ Cloud type } & \multirow[b]{2}{*}{$\begin{array}{c}\text { RASTA suitable for Cloudsat } \\
\text { evaluation? }\end{array}$} \\
\hline & $\begin{array}{l}\text { Start time } \\
\text { (UTC) }\end{array}$ & $\begin{array}{l}\text { End time } \\
\text { (UTC) }\end{array}$ & & \\
\hline \multicolumn{5}{|l|}{ AMMA } \\
\hline 09 Sep 2006 & 1300 & 1450 & Sporadic deep convection over land & No \\
\hline 20 Sep 2006 & 1350 & 1635 & Thin $\mathrm{Ci}$ over ocean & No \\
\hline 21 Sep 2006 & 215 & 430 & Thin Ci over ocean & No \\
\hline 22 Sep 2006 & 1350 & 1650 & MCS anvil over land and ocean & Yes (ocean backscatter) \\
\hline \multicolumn{5}{|l|}{ CIRCLE-2 } \\
\hline 13 May 2007 & 1110 & 1405 & Convection over land & No \\
\hline 16 May 2007 & 1220 & 1530 & Thin frontal $\mathrm{Ci}$ over ocean & Yes (ocean backscatter) \\
\hline 20 May 2007 & 1110 & 1415 & Broken $\mathrm{Ci}+$ convection over land & Yes (ice clouds) \\
\hline 25 May 2007 & 1120 & 1500 & Thin Ci layer over ocean & Yes (ice clouds and ocean backscatter) \\
\hline 26 May 2007 & 1100 & 1400 & Outflow Ci over land & Yes (ice clouds) \\
\hline
\end{tabular}

much longer time series. In addition, our aim is to assess the Cloudsat products both for midlatitude and tropical ice clouds in order to span a sample as representative as possible of ice clouds at global scale. We are also currently conducting an airborne radar-lidar experiment in arctic mixed-phase clouds, which should soon be available to extend the present assessment study to polar clouds.

Gaseous attenuation calculations at $95 \mathrm{GHz}$ were performed through the model developed by Liebe et al. (1993) for all radar observations used in this study. The input thermodynamic variables are from the European Centre for Medium-Range Weather Forecasts (ECMWF) model in all cases. The imaginary part of the complex refractivity was computed as the sum of contributions associated with molecular oxygen (the pressure-broadening and nonresonant terms) and water vapor (the pressurebroadening and continuum terms). Under relatively warm and moist atmospheric conditions [e.g., the tropical model presented by Ellingson et al. (1991)], the model by Ulaby et al. (1981) produces two-way path-integrated attenuation 0.2-dB larger than that by Liebe et al. (1993) for a nadirviewing airborne radar at $95 \mathrm{GHz}$ flying at $4 \mathrm{~km}$. This number is probably a good estimate of the error of these corrections on path-integrated attenuation correction.

In the following subsections, we describe the methodology used for the airborne and ground-based evaluations and we describe which observations have been used.

\section{a. The airborne cloud radar observations}

The present evaluation is conducted using flights performed under the A-Train track during the AMMA (Redelsperger et al. 2006) and the French-German CIRCLE- 2 campaigns by the French Falcon 20 equipped with the radar-lidar (RALI) instrument. This RALI instrument (Protat et al. 2004) is the airborne combination of two instruments: a multiantenna (3 antennas downward, 2 antennas upward) 95-GHz Doppler cloud radar named Radar Aéroporté et Sol de Télédétection des Propriétés Nuageuses (RASTA) and a triple-wavelength $(355,532$, and $1064 \mathrm{~nm})$ and dual-polarization $(532 \mathrm{~nm})$ backscatter lidar.

Direct comparisons between spaceborne and airborne cloud radars can be performed using collocated measurements of clouds or the earth surface (ocean or land). Regarding the surface of the earth, the comparisons are known to be more challenging over land surface than over ocean owing to the fact that the land surface backscatter is a function of the incidence angle, the dielectric constant, and the surface roughness parameter. As a result, we have restricted the comparisons to the ocean surface. Regarding clouds, the two main factors that can produce differences between the spaceborne and airborne radars are the differential attenuation of the two beams (when looking upward with the airborne radar) and the differential multiple scattering. To minimize these potential sources of discrepancies between the spaceborne and airborne observations, the nonprecipitating ice clouds are the best targets, because they are characterized by a negligible attenuation and there is no significant multiple scattering occurring in the wider Cloudsat beam. Therefore, in the following, we have only retained flights in which nonprecipitating ice clouds were sampled by both instruments. Table 1 summarizes the main characteristics of the flights performed along the track of the A-Train during the AMMA and CIRCLE-2 field campaigns. Among these flights, two flights have been performed over the ocean during CIRCLE-2 and three during AMMA. Given the degraded sensitivity of RASTA during AMMA (for discussion, see Bouniol et al. 2008) and the fact that the flight altitude was very high during the 20 and 21 September 2006 flights (11-12-km altitude), the ocean surface backscatter during AMMA was best measured during the 22 September AMMA flight. Therefore, in our comparisons of the ocean 
TABLE 2. Ground-based radar observational periods selected for statistical comparisons with Cloudsat measurements and products.

\begin{tabular}{lccc}
\hline \hline \multicolumn{1}{c}{ Location (lat, lon) } & $\begin{array}{c}\text { Radar frequency } \\
\text { (name) }\end{array}$ & $\begin{array}{c}\text { Radar sensitivity } \\
(\mathrm{dBZ} \text { at 10 km) }\end{array}$ & \multicolumn{1}{c}{ Observational period } \\
\hline Darwin, Australia $\left(12.425^{\circ} \mathrm{S}, 130.891^{\circ} \mathrm{E}\right)$ & $35 \mathrm{GHz}(\mathrm{MMCR})$ & -41 (cirrus mode) & December 2006-April 2007 \\
Darwin, Australia $\left(12.425^{\circ} \mathrm{S}, 130.891^{\circ} \mathrm{E}\right)$ & $5 \mathrm{GHz}(\mathrm{CPOL})$ & -21 & December 2006-April 2007 \\
Niamey, Niger $\left(13.477^{\circ} \mathrm{N}, 2.176^{\circ} \mathrm{E}\right)$ & $94 \mathrm{GHz}(\mathrm{WACR})$ & -34 & 21 June 2006-December 2006 \\
Lindenberg, Germany $\left(52.209^{\circ} \mathrm{N}, 14.122^{\circ} \mathrm{E}\right)$ & $36 \mathrm{GHz}(\mathrm{MIRA})$ & -40 & August 2006-April 2007 \\
COPS site, Germany $\left(48.540^{\circ} \mathrm{N}, 8.397^{\circ} \mathrm{E}\right)$ & $94 \mathrm{GHz}(\mathrm{WACR})$ & -34 & April 2007-December 2007 \\
Palaiseau, France $\left(48.713^{\circ} \mathrm{N}, 2.208^{\circ} \mathrm{E}\right)$ & $95 \mathrm{GHz}(\mathrm{RASTA})$ & -30 & December 2006-February 2007 \\
\hline
\end{tabular}

backscatter, we have retained only the 22 September 2006 flight from AMMA and the two CIRCLE-2 flights on 16 and 25 May 2007.

Regarding ice clouds, Bouniol et al. (2008) showed that direct comparisons with Cloudsat within the 22 September 2006 thick anvil could not be quantitatively exploited, because of the contamination of both radar measurements by attenuation due to supercooled liquid water and/or large ice particles and by the multiple scattering in the Cloudsat beam. Among the CIRCLE-2 flights, three of them included ice clouds at the approximate time of overpass (see Table 1) and are therefore used in the present study: the 20, 25, and 26 May 2007 cases.

\section{$b$. The ground-based cloud radar observations}

The ground-based observations selected for this evaluation of Cloudsat have been collected over three midlatitude sites and two tropical sites:

- the 95-GHz RASTA radar at the Site Instrumental de Recherche par Télédétection Atmosphérique (SIRTA) site in Palaiseau, France (Haeffelin et al. 2005);

- the 35.5-GHz millimeter-wave radar (MIRA) in Lindenberg, Germany;

- the 95-GHz mobile facility W-band ARM cloud radar (WACR) deployed during the Convective and Orographically induced Precipitation Study (COPS) experiment in the Murg Valley, Germany;

- the 35-GHz ARM millimeter-wave cloud radar (MMCR) at Darwin, Australia; and

- the 94-GHz mobile facility WACR radar at Niamey, Niger.

The periods considered for the statistical analysis of the cloud properties are described in Table 2. Generally, the ground-based radars have a lower noise floor than Cloudsat, which is around $-29 \mathrm{dBZ}$ for the whole troposphere (Tanelli et al. 2008), except in the upper part of the troposphere for some of them. As a result, we have carefully degraded all radar observations to the same detection level (sensitivity) prior to any comparison. To compare ground-based and spaceborne radar observations, we have considered Cloudsat data from a radius of $200 \mathrm{~km}$ around the sites and different time intervals around the time of satellite overpass. These numbers result from a trade-off between a sufficiently large number of observations to reach statistical significance and a reasonable invariance of the reflectivity and basic cloud properties statistics. Sensitivity studies are reported in the following to address this issue. Finally, the geometry of observations is different (the spaceborne instrument samples the cloud from top to base, whereas the groundbased instrument does it the other way around). This has particularly important implications for the comparison of ground-based and spaceborne ice cloud observations.

Indeed, most ice cloud observations from space will be reasonably unattenuated (except in mixed-phase clouds characterized by significant amounts of supercooled liquid water). In contrast, a significant portion of the ice cloud observations from the ground will be strongly attenuated by any liquid cloud below ice clouds or by the liquid part of the deep convective systems to which they belong. As a result, we have carefully separated in the Cloudsat datasets the "ice cloud" profiles (which do not have a liquid layer below) and the "convective ice" profiles (which are ice clouds above liquid layers or the ice part of a convective system). This separation is achieved using a two-step procedure. First, we identify the altitude of the $0^{\circ} \mathrm{C}$ isotherm altitude from the Cloudsat ECMWF auxiliary (AUX) product (which is an extraction of the ECMWF profiles collocated with the Cloudsat reflectivity profiles), and we assume that at altitudes greater than this $0^{\circ} \mathrm{C}$ isotherm altitude we have ice clouds and below we have liquid clouds (the occurrences of supercooled liquid water is therefore treated as ice in the present study, but it is also what is done with the ground-based observations). Second, if there is $90 \%$ or more of the liquid water part of the profile filled with Cloudsat reflectivities larger than the Cloudsat detection level, then we classify the ice part of this profile as a convective ice profile; otherwise, the ice part of the profile is classified as an ice cloud profile. A similar (although much more elaborated) separation has been carried out with the ground-based observations using the "target categorization" approach (detailed documentation available online at http://www.met.rdg.ac.uk/ $\sim$ swrhgnrj/publications/categorization.pdf; Delanoë and 
Hogan 2008), which consists in classifying each observed scene as a meteorological or nonmeteorological target from the cloud radar, lidar, and microwave radiometer measurements and then assigning a water phase (liquid, ice, or mixed-phase) and a data-quality flag to each cloud scene.

In what follows, we compare the statistical properties derived from the ice cloud profiles only, except over Darwin, for which the Cloudsat convective ice profiles are evaluated against observations from the C-band polarimetric (CPOL) scanning dual-polarization Doppler research radar (Keenan et al. 1998) observations.

\section{Assessment of Cloudsat calibration from airborne cloud radar observations}

\section{a. The calibration of the airborne cloud radar RASTA}

The calibration of the airborne Doppler cloud radar RASTA has been achieved using the ocean surface backscatter (the so-called $\sigma_{0}$ method; Li et al. 2005). The principle of this method is that the ocean backscatter is roughly independent of surface wind for an incidence angle of $9^{\circ}-10^{\circ}$, with a value around $7 \mathrm{~dB}$. This calibration procedure using the ocean surface has demonstrated its good performance in the context of the Tropical Rainfall Measuring Mission (e.g., Okamoto et al. 2002). Note that the Cloudsat calibration has also been evaluated using this $\sigma_{0}$ method (Tanelli et al. 2008). Two flights were devoted specifically to this calibration (one during AMMA and one during CIRCLE-2). The RASTA calibration results are reported in Bouniol et al. (2008). This technique is expected to produce a calibration accurate to within $1 \mathrm{~dB}$ or so (e.g., Li et al. 2005), especially if a large number of $\sigma_{0}$ samples are collected. We believe that this accuracy has been achieved because two flights of about $1.5 \mathrm{~h}$ sampling the ocean backscatter were performed in various surface wind conditions, and dropsondes were launched at regular intervals to update the gaseous attenuation correction.

\section{b. Comparison of Cloudsat and RASTA ocean backscatter}

As discussed in section 2, direct comparisons between Cloudsat and RASTA can be performed by using collocated measurements of the ocean backscatter during the 22 September 2006 flight from AMMA and the two CIRCLE-2 flights on 16 and 25 May 2007.

Figure 1 illustrates the analysis performed for each flight using the 16 May 2007 flight during CIRCLE-2. The track of the French Falcon 20 carrying RASTA is shown in Fig. 1a (black line), as well as the Cloudsat track (gray line and best coincidence with airborne observations highlighted in red). The ocean surface backscatters are shown in Fig. 1b, and the Doppler measurement of RASTA (not corrected for the aircraft speed) is shown in Fig. 1c. When the Doppler is zero, it means that RASTA measures the surface backscatter at exact vertical incidence, whereas any departure from the zero Doppler will indicate that the measurement is made slightly off nadir. The two time series of Cloudsat (gray) and RASTA (black) $\sigma_{0}$ are in good agreement (Fig. 1b), except on the left part of the time series, which after inspection of the RASTA Doppler velocity appears to be due to large departures from nadir (Fig. 1c), corresponding to lower $\sigma_{0}$ values for RASTA expected from theory (Cox and Munk 1954; Wu 1972; Wu 1990; Freilich and Vanhoff 2003). The mean difference (denoted as $\left.\Delta \sigma_{0}=\sigma_{0 \text { Cloudsat }}-\sigma_{\text {ORASTA }}\right)$ is $0.2 \pm 0.8 \mathrm{~dB}$ for this flight, which is fairly small. As expected, the largest differences are obtained for the largest Doppler velocities (see Fig. 1e), and these $\Delta \sigma_{0}$ values are positive, which is in agreement with the theory (departures from nadir incidence produce smaller backscatter). The $\Delta \sigma_{0}$ values obtained for the other CIRCLE-2 flight (25 May 2007) and the AMMA flight (22 September 2006) are very similar $\left(\Delta \sigma_{0}=0.3 \pm 1.2 \mathrm{~dB}\right.$ and $\left.\Delta \sigma_{0}=-0.1 \pm 1.7 \mathrm{~dB}\right)$.

During the 25 May 2007 flight, the aircraft flew four successive straight flight patterns along the Cloudsat ground track (denoted as 1-4 in Figs. 1f,g for the following patterns, respectively: one before the satellite overpass, one collocated in time, and two after the satellite overpass), corresponding to temporal differences of up to one hour between the airborne and spaceborne observations. This provides an opportunity to evaluate how crucial the temporal coincidence of observations is when comparing ocean surface returns. The corresponding differences are plotted in Fig. 1f and they are plotted as a function of the Doppler velocity in Fig. 1g. As can be seen from these figures, there is not much degradation in the agreement between spaceborne and airborne ocean backscattering between the four flight portions. More quantitatively, the differences are $\Delta \sigma_{0}=$ $0.5 \pm 0.8 \mathrm{~dB}, \Delta \sigma_{0}=0.0 \pm 0.4 \mathrm{~dB}$, and $\Delta \sigma_{0}=0.6 \pm 0.7 \mathrm{~dB}$ for the three noncoincident flight portions 1,3 , and 4 , respectively. It is striking to see that the standard deviation does not increase with the temporal lag between the airborne and spaceborne observations, which indicates that in the present case the ocean surface backscatter characteristics were sufficiently stationary at the 1-h time scale for aircraft-satellite comparisons.

When taking all the $\sigma_{0}$ measurements from the three flights together, the difference is $\Delta \sigma_{0}=0.4 \pm 1.0 \mathrm{~dB}$, which will be retained as the final result of this direct comparison between Cloudsat and RASTA ocean surface backscatters. This 0.4-dB mean difference is smaller than the expected accuracy of the calibration of RASTA 

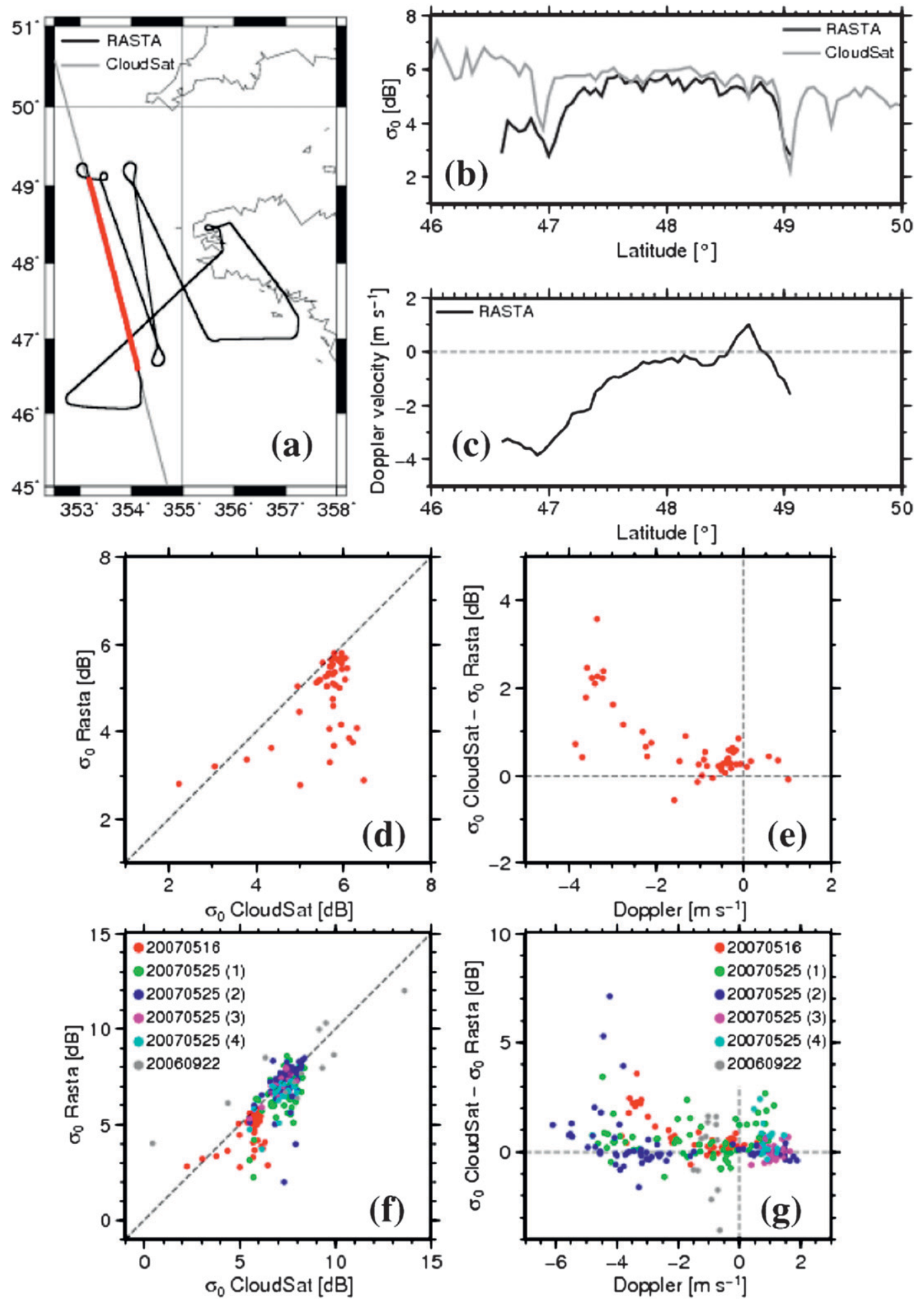

FIG. 1. (a) Cloudsat (solid gray line) and RASTA (solid black line) tracks for the 16 May 2007 CIRCLE-2 flight. The solid red line depicts the best temporally coincident track. (b) Ocean surface backscatter measured by Cloudsat (gray) and RASTA (black) as a function of latitude, filtered using $0.1^{\circ}$ latitude bins. (c) Doppler velocity ( $\mathrm{m} \mathrm{s}^{-1}$ ) measured at the ocean surface by RASTA (black), filtered using $0.1^{\circ}$ latitude bins. Scatterplot of RASTA $\sigma_{0}$ as a function of Cloudsat $\sigma_{0}$ for (d) the 16 May 2007 flight only and (f) all of the flights included in the statistical analysis (colors correspond to different flights). Difference in $\sigma_{0}$ (Cloudsat - RASTA) as a function of the measured Doppler velocity for (e) the 16 May 2007 flight and (g) all of the flights included in the statistical analysis. 
(around $1 \mathrm{~dB}$ ). From these ocean backscatter comparisons, we therefore conclude that the reflectivities agree within the expected RASTA calibration uncertainty.

\section{c. Direct comparison of Cloudsat and RASTA ice cloud reflectivities}

Although direct comparisons are not possible with the AMMA 22 September 2006 flight because of attenuation and multiple scattering in the ice part of the thick mesoscale convective system anvil (Bouniol et al. 2008), three flights within the Cloudsat track can be used from CIRCLE-2, as discussed in section 2. Figures 2-4 show the high-resolution airborne RASTA radar data for these flights (the 20,26, and 25 May cases), as well as the same cloud scene derived from the RASTA observations, but at a scale and sensitivity comparable with the Cloudsat observations. To do so, we have first averaged the RASTA measurements in order to match the Cloudsat resolution $(1.7 \mathrm{~km}$ along track and $500 \mathrm{~m}$ vertically), and then, after the averaging, we have discarded all RASTA observations below the Cloudsat sensitivity threshold (around $-29 \mathrm{dBZ}$ for the whole troposphere). In each figure, the bottom panel is the corresponding Cloudsat measurements with all observations below the RASTA sensitivity threshold $[-31.5 \mathrm{dBZ}+20 \log (r)$, where $r$ is the radar range in kilometers] removed. The difference in conventions for the refractive index $(0.75$ for Cloudsat and 0.93 for RASTA) has been accounted for in the plots and in the computation of the statistics of the difference between the two radars.

The 20 May 2007 cirrus case (Fig. 2) is the best one in terms of cloud cover and temporal coincidence $(8 \mathrm{~s})$ of the airborne and ground-based observations. However, the spatial coincidence is not the best of all flights, with spatial mismatches ranging from 200 to $400 \mathrm{~m}$ off the Cloudsat track (see the color display of each point on Fig. 5). The 26 May 2007 thicker cirrus case (Fig. 3) is very good in terms of spatial and temporal coincidence with the satellite observations (less than $100 \mathrm{~m}$ and $130 \mathrm{~s}$; see Fig. 6). However, its internal structure apparently varies very rapidly during the time of observations (see differences in the upper part of the cirrus cloud on Fig. 3). This is confirmed by inspecting the airborne observations from the previous and next legs (not shown). The 25 May 2007 midlevel ice cloud case (Fig. 4) is good in terms of spatial coincidence (less than $200 \mathrm{~m}$; see Fig. 7), but there was a time difference of 3-5 min between the airborne and spaceborne observations. Thus, this case does not provide many common cloud samples, as can be seen from Fig. 4 .

Generally speaking, once the airborne radar data are averaged to the Cloudsat resolution, the qualitative consistency between the two observations is quite good, except for the upper part of the 26 May 2007 case (Fig. 3).
The quantitative assessment of the difference for the 20 May 2007 case (assumed to be the best case because of the large amount of common cloud samples), when all data shown in Fig. 2 are included, is given in the top panel of Fig. 5. We will examine $\Delta Z=Z_{\text {Cloudsat }}-Z_{\text {RASTA }}$ in the following: for the 20 May case, $\Delta Z=0.9 \mathrm{~dB}$, with a very large standard deviation of $4 \mathrm{dBZ}$, which means that Cloudsat measures slightly larger reflectivities than RASTA. The potential reasons for this fairly large standard deviation are the temporal and spatial lag of the observations, the possible slight geolocation errors of the two instruments, and the partial beam filling of the Cloudsat measurements at cloud edges. To minimize the effect of spatial and temporal mismatch between observations, we have used thresholds on these three parameters. If we restrict the time lag to an absolute maximum of $3 \mathrm{~min}$, then $\Delta Z$ is unaffected but its standard deviation is reduced to $3.2 \mathrm{~dB}$ (Fig. 5, middle). We do not observe such a reduction of the standard deviation of the error when setting a threshold on the spatial mismatch, and the mean difference is unchanged (not shown). The effect of partial beam filling on cloud edges of the Cloudsat measurements has been minimized by calculating a normalized cloud height for each profile in both the airborne and spaceborne observations and removing the observations for normalized cloud heights less than 0.1 and greater than 0.9 (cloud base and top, respectively). If we apply this procedure, we find that $\Delta Z$ is almost unaffected $(\Delta Z=$ $1.0 \mathrm{~dB}$ ), whereas the standard deviation is reduced further to $2.9 \mathrm{~dB}$ (bottom panel of Fig. 5). These numbers are unchanged if thresholds of 0.2 and 0.8 are used for the normalized cloud height (not shown).

Because of much smaller amounts of common cloud samples for the two other cases, such refinements are not possible, and we have therefore retained all the points in the difference statistics. These statistics are shown for the 26 and 25 May cases on Figs. 6 and 7, respectively. The difference found is $\Delta Z=2.3 \pm 4.2 \mathrm{~dB}$ for the 26 May case (Fig. 6) and $\Delta Z=1.1 \pm 2.1 \mathrm{~dB}$ for the 25 May case. It is noteworthy that the estimate from the 25 May case is similar to that found with the 20 May case $(\Delta Z=$ $1.0 \mathrm{~dB})$. We have checked that the larger difference obtained for the 26 May case resulted from the observed large differences in the upper-right part of the cloud structure, by restricting the comparison to heights lower than $8 \mathrm{~km}$. In this case, $\Delta Z$ reduces to $1.5 \mathrm{~dB}$ and the standard deviation reduces to $3.5 \mathrm{~dB}$.

In conclusion, by comparing reasonably collocated airborne and spaceborne ice cloud samples at the same resolution, we find that Cloudsat measures reflectivities about $1 \mathrm{~dB}$ higher than the airborne RASTA radar. Given the fact that the calibration accuracy of the airborne radar is about $1 \mathrm{~dB}$, we conclude that the spaceborne and 

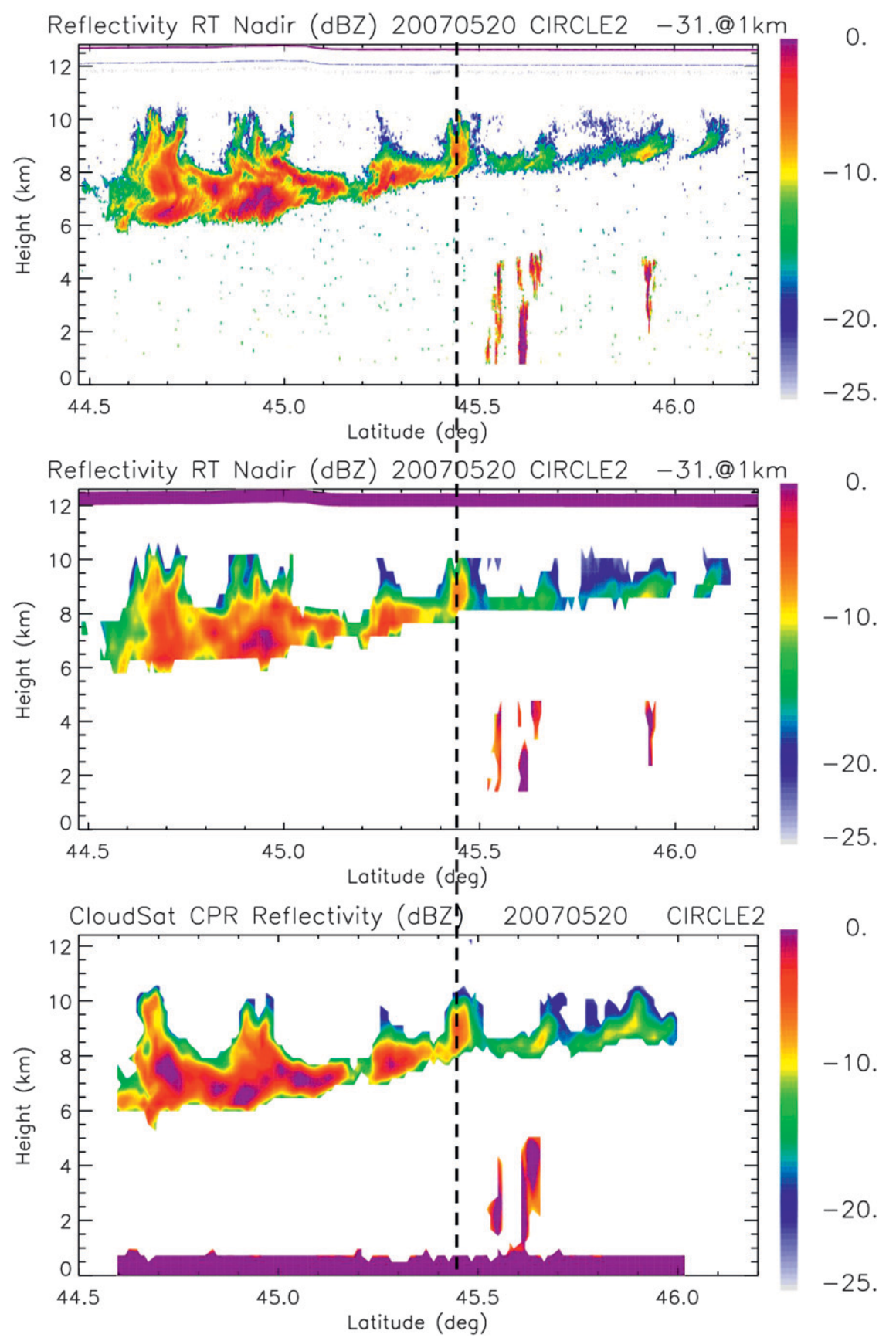

FIG. 2. Latitude-height reflectivity plots as observed (top) by RASTA at full resolution and sensitivity, (middle) by RASTA at Cloudsat resolution and sensitivity, and (bottom) by the Cloudsat radar at RASTA sensitivity on 20 May 2007 over western Europe during CIRCLE-2. The thick purple line at around 12-km height in (a),(b) is the French Falcon 20 track. The satellite overpass (shown as a thick dashed line) occurred at a time corresponding to the latitude of $45.44^{\circ}$ on the plot.

airborne radar reflectivities agree within this calibration uncertainty. This is in agreement with the findings of the previous section, in which collocated ocean backscatter measurements at vertical incidence had been compared. The relatively large standard deviation of the difference
(2-3 dB) leads to the conclusion that this type of direct comparison using ice clouds is of limited value if one wants to achieve a more accurate evaluation of the spaceborne radar calibration than that proposed in the present study. It is also larger than the standard deviation 

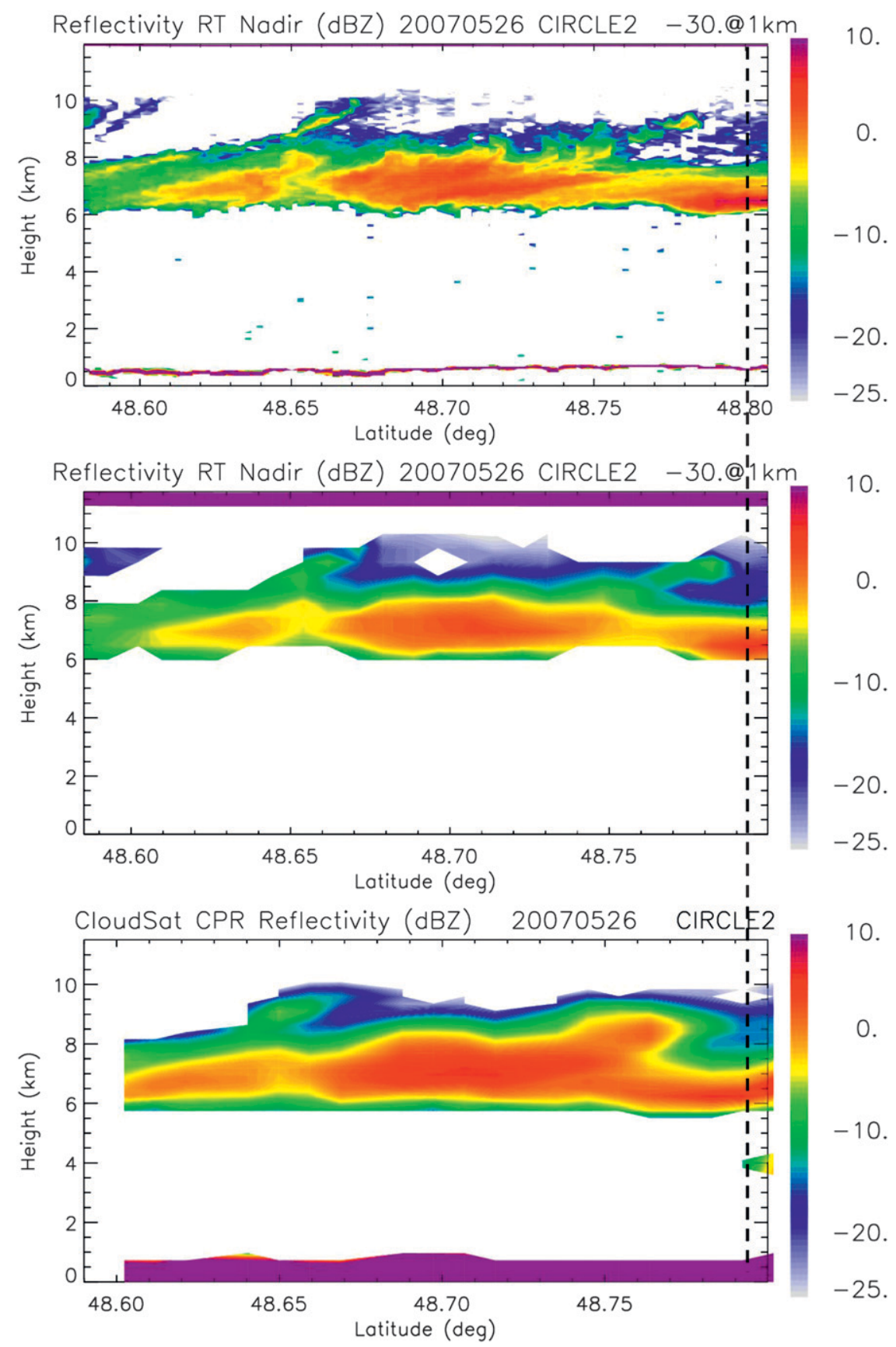

FIG. 3. As in Fig. 2, but for the 26 May 2007 case study. For this case, the satellite overpass (shown as a thick dashed line) occurred at a time corresponding to the latitude of $48.80^{\circ}$ on the plot.

of the difference obtained when comparing the ocean surface backscatter (around $1 \mathrm{~dB}$ ), which seems to indicate that the ocean surface is an easier target for spaceborne radar assessment than ice clouds. In the near future, different assessments of the Cloudsat calibration from all good underflights of the Cloudsat track made worldwide during the different validation campaigns will also be compared.

\section{Assessment of Cloudsat reflectivities and macrophysical ice cloud properties from statistical comparisons with ground-based cloud radar observations}

\section{a. Discussion and sensitivity tests}

In this section, the statistical properties of ice clouds derived from continuous ground-based Doppler radar 

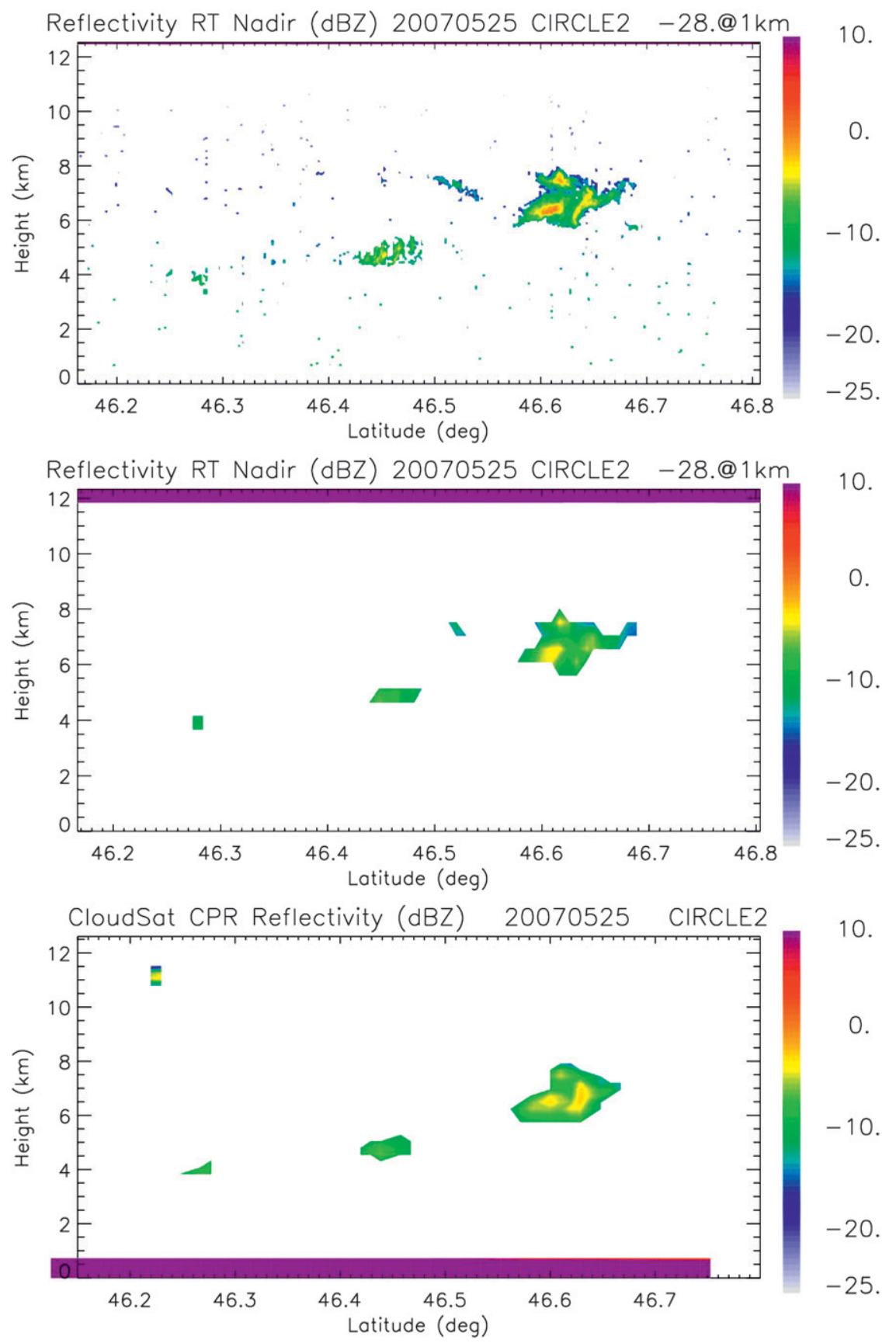

FIG. 4. As in Fig. 2, but for the 25 May 2007 case study. For this case, the satellite overpass occurred around 4 min before this scene had been sampled by the airborne radar (longitude would not mean anything in this case to compare cloud structure).

observations collected in different regions of the world (see Table 2) are used as references to assess how well the ground-based and spaceborne radar reflectivities and morphological cloud properties (cloud base, top, and thickness) compare with each other. This will provide an additional assessment of the Cloudsat reflectivities, which is complementary to the assessment carried out in section
3 with airborne radar observations (statistical versus direct comparison). It is also a good way of checking if the underlying assumptions of the statistical approach are valid. Indeed, as briefly mentioned in section 2 , for these comparisons we need to assume that the statistical properties of ice clouds are reasonably invariant within a given range from the ground-based site location. We 

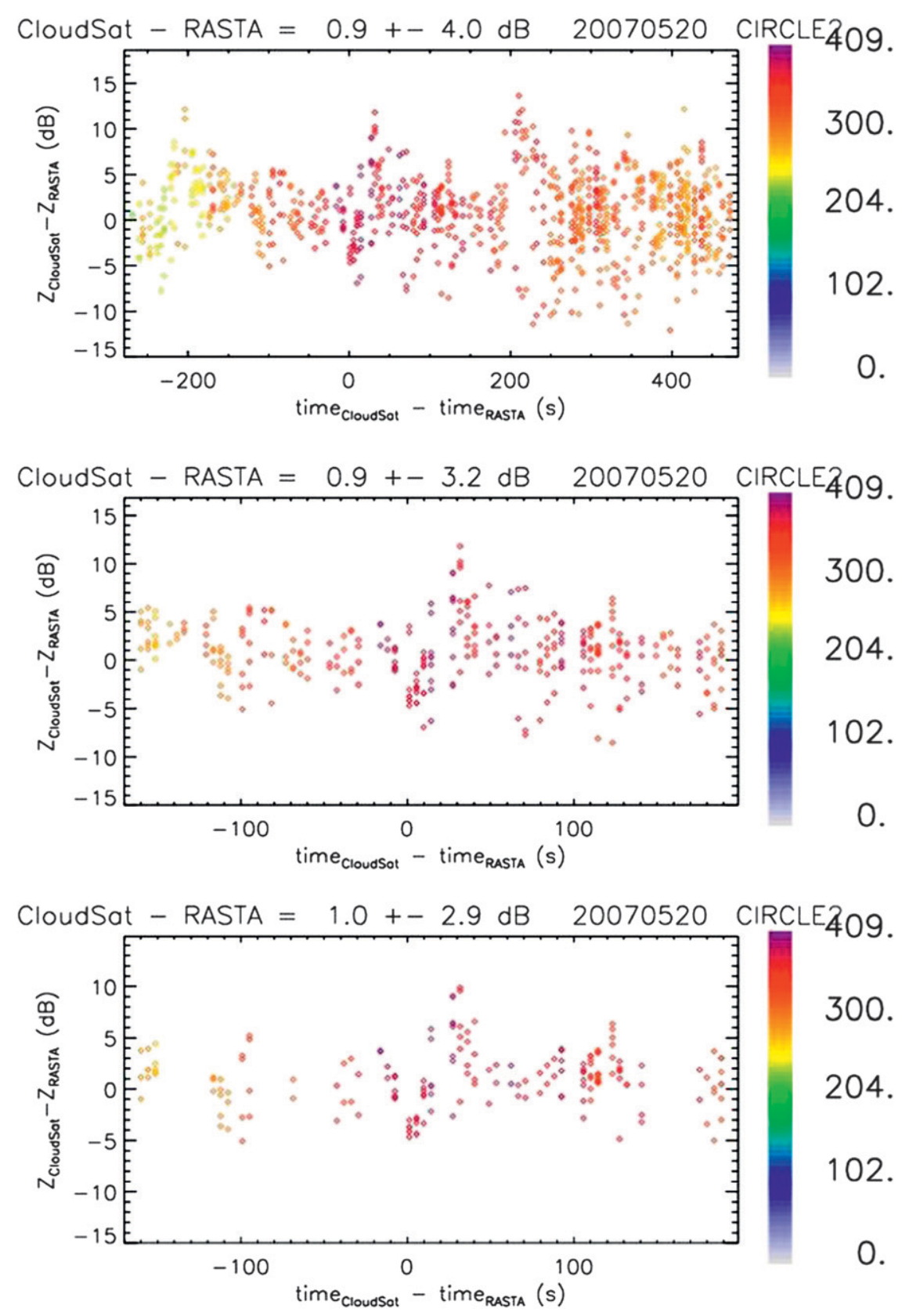

FIG. 5. The difference between the spaceborne radar and the airborne radar as a function of the time lag between these observations for the 20 May 2007 case study in Fig. 2. The color bar indicates the distance between the observations as well for each observation. The graphs are for when (top) the whole straight-flight pattern is considered, (middle) restricting to $\pm 3 \mathrm{~min}$ around the overpass time, and (bottom) restricting to $\pm 3 \mathrm{~min}$ around the overpass time and $0.1-0.9$ normalized cloud heights. The mean and standard deviation of the difference of (top)-(bottom) is given for each.

also need to consider a time lag between these spaceborne and ground-based observations to minimize differences because of possible diurnal variability of the ice cloud properties. Figure 8 shows the sensitivity of the probability density function (PDF) of reflectivity and cloud thickness (results discussed therein are similar when the cloud-top or cloud-base heights are considered; not shown) and mean vertical profile of reflectivity to the maximum time lag (on the ground-based radar reflectivities; Fig. 8, left column) and maximum distance (on 


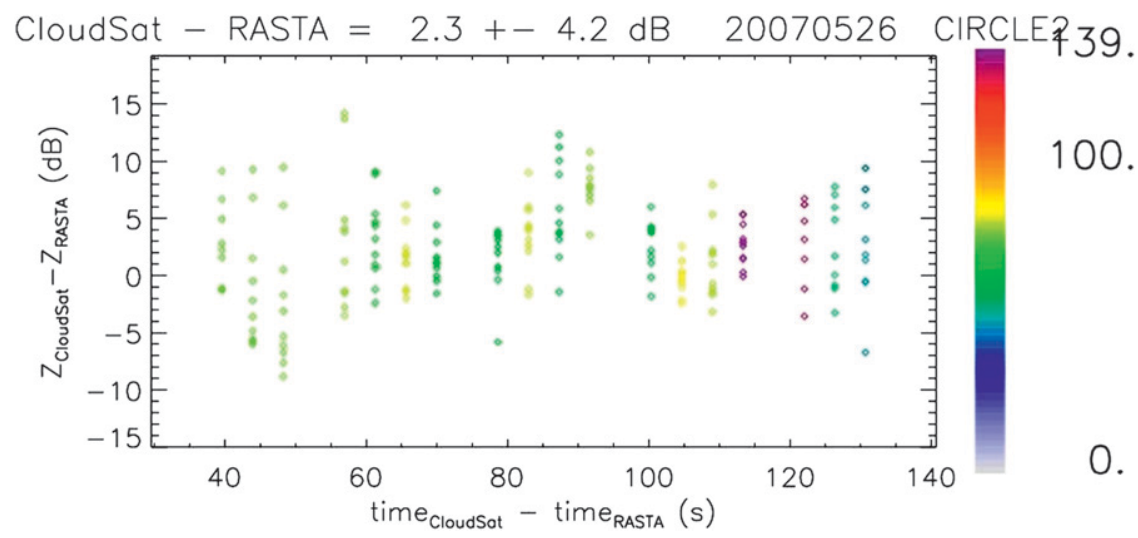

FIG. 6. The difference between the spaceborne radar and the airborne radar as a function of the time lag between these observations for the 26 May 2007 case study in Fig. 3. The color bar indicates the distance between the observations as well for each observation. The mean and standard deviation of the difference are also indicated.

the Cloudsat reflectivities; Fig. 8, right column). It is seen that the maximum time lag over the Darwin site has little impact on the PDFs and the mean vertical profile (Fig. 8, left column). The computation of the mean difference and standard deviation of the difference between the reflectivities derived from the "no time lag" and " \pm 1 -h time lag" cases are 0.03 and 0.15 , respectively, which is fairly small. This is also true over the SIRTA and Lindenberg sites (not shown), somewhat less over the Niamey and COPS sites for which the standard deviation of the difference is larger ( $0.6 \mathrm{~dB}$ over Niamey, 0.5 for COPS), but remains relatively small. The effect of the maximum distance clearly has a larger impact, especially on the PDFs. A trade-off must be found here, because reducing the maximum distance could have two opposite effects: the negative effect of reducing the statistical significance of the Cloudsat-derived statistics, and the positive effect of improving the collocation of the ground-based and Cloudsat observations. It is observed in Fig. 8 (and the same also applies for all the other sites, not shown) that the choice of a maximum distance smaller than $200 \mathrm{~km}$ systematically tends to degrade the agreement between the ground-based and spaceborne observations by modifying the shapes of the PDFs (see large peaks produced in Fig. 8, top-middle, right column) and introducing more structures in the mean vertical profiles (Fig. 8, bottom, right column). As discussed previously, it indicates that the statistics derived from Cloudsat observations become questionable for 100 and $50 \mathrm{~km}$ distances for the time spans selected for the comparisons. To quantify this effect, we have taken the reflectivities derived from considering a $200-\mathrm{km}$ radius around the ground-based site and estimated the mean difference and standard deviation of the difference with the reflectivities derived from a $50-\mathrm{km}$ radius and a $100-\mathrm{km}$ radius. It must be noted that the statistics derived from a 300-km radius (not shown) has been derived and is found to be virtually identical to the $200-\mathrm{km}$ statistics, which indicates that there is no point in

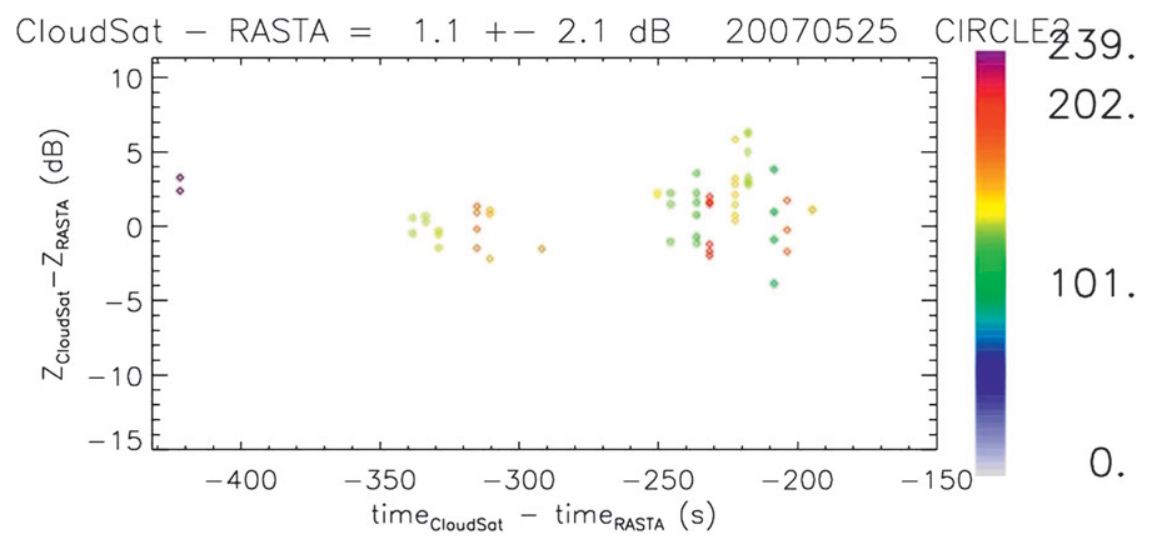

FIG. 7. As in Fig. 6, but for the 25 May 2007 case study in Fig. 4. 

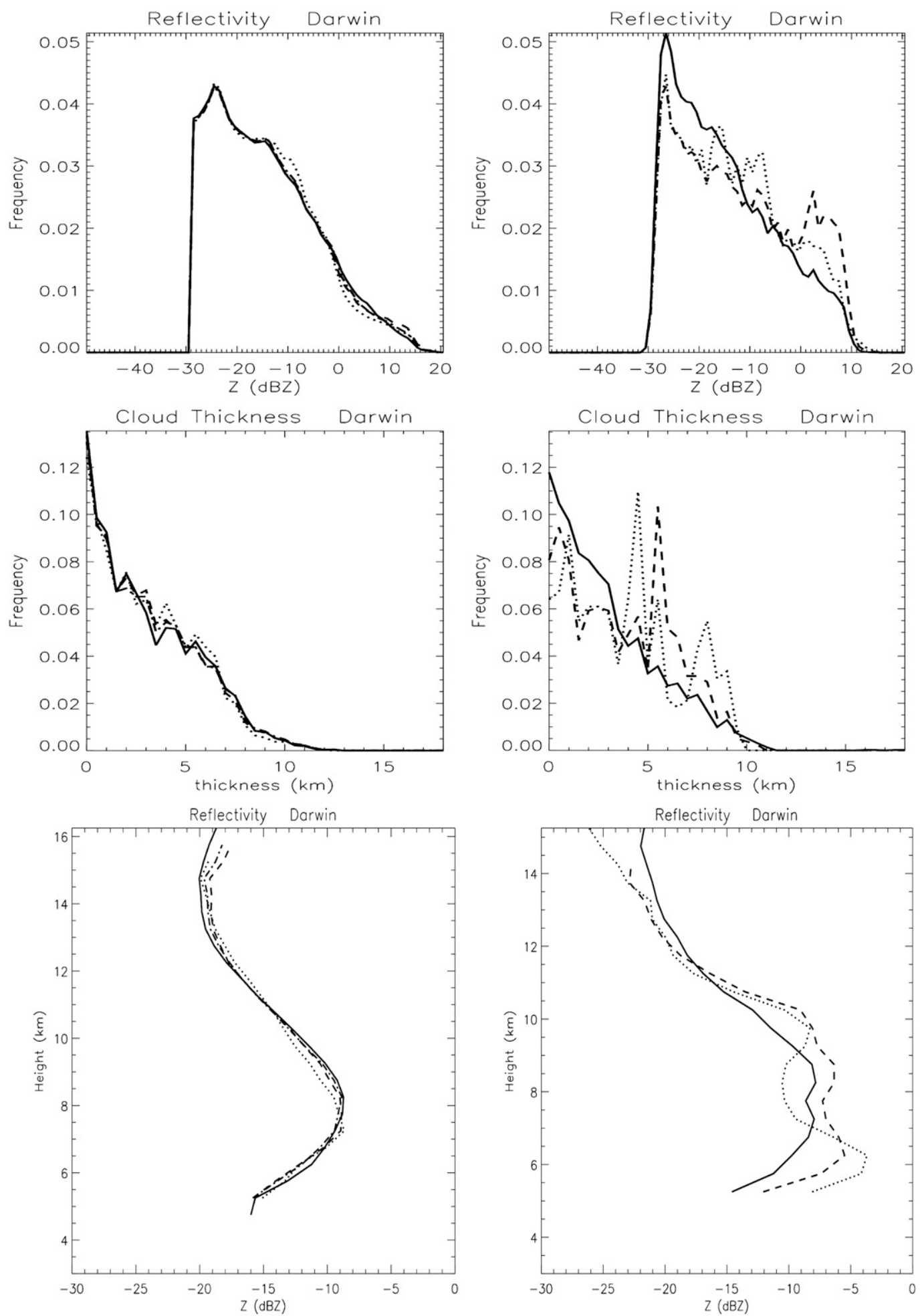

FIG. 8. Assessment of the sensitivity of reflectivity statistics to (left) the maximum time lag around Cloudsat overpass and (right) the maximum distance of Cloudsat observations to the ground-based site. PDFs of (top) radar reflectivity, (middle) cloud thickness, and (bottom) mean vertical profiles of radar reflectivity. The solid line on the plots of (left) is when no time lag is applied to the Darwin ARM radar to compute the statistics, and dotted, dashed and dashed-dotted lines are when $\pm 1, \pm 2$, and $\pm 3 \mathrm{~h}$ around the overpass time are considered to build up the statistics, respectively. Solid, dashed, and dotted lines on the plots of (right) are when a 200-, 100-, and 50-km radius is considered to build the Cloudsat statistics, respectively. 
increasing the radius more than $200 \mathrm{~km}$ around the ground-based sites. The mean difference and standard deviation of the difference are -1.2 and 0.51 , respectively, when comparing the reflectivities using the 100and $200-\mathrm{km}$ radius and -0.2 and 0.70 , respectively, when comparing the reflectivities using the $50-$ and $200-\mathrm{km}$ profiles. These numbers are clearly much larger than those obtained for the impact of considering different time lags (0.03 and 0.15). This result applies to all the other sites included in the present statistical analysis. Increasing the time span of these comparisons could be another option to reduce the horizontal scale for which we assume an invariance of the ice cloud properties, but we do not have the resources currently to process more data for these comparisons. In what follows, we therefore retained the 200-km maximum distance as a good trade-off. Regarding the time lag, there is no objective way to say what the best trade-off is, but anyway the effect does not appear to be very large, so for the statistical evaluation we have considered both the statistics derived without using any time lag and the statistics derived using a \pm 1 -h maximum time difference. This allows us to evaluate how variable our numbers are with respect to this assumption.

\section{b. The wavelength difference between Cloudsat and the ground-based radars}

Another important aspect that needs to be addressed is that three of the five ground-based radars used in this study are operating at a frequency lower than that of Cloudsat (Darwin and Lindenberg at $35 \mathrm{GHz}$ and CPOL at $5 \mathrm{GHz}$ ); therefore, they are less prone to the so-called Mie effects, which occur when the particle diameter is no longer negligible with respect to the radar wavelength. A statistical method is proposed in what follows to take this effect into account. The principle is to "convert" the 5- and 35-GHz observations into pseudo95-GHz observations. The rationale for doing this is that although there are some assumptions in this conversion calculation, it will certainly yield more comparable reflectivities than if no correction is applied. However, it is difficult to estimate how accurate this conversion is on individual profiles. A statistical evaluation of this correction will be given in section 5 . For this purpose, we use a large database of in situ ice cloud microphysical measurements of the ice particle size distribution gathered in different international field experiments (as described in Delanoë et al. 2005), assume the Heymsfield et al. (2007) temperature-dependent mass-dimension relationship, and calculate radar reflectivity at the three wavelengths of interest for the present study by using Mie theory. For the Mie calculations, we have used the spherical assumption for size, with the maximum di- mension measured by the probes as the diameter of the spheres, but we corrected the refractive index by assuming the Heymsfield et al. (2007) density for the ice particles instead of taking the density of solid ice, following the "fractional refractive index" approach proposed by Oguchi (1983). More details are given in Protat et al. (2007). This is equivalent to the "equivalent melting diameter" approach described in Donovan et al. (2004), which has proven to well reproduce results from more complex calculations, such as those using the discrete dipole approximation and prescribed particle habits and particle size distributions (see latest results in Weinman and Kim 2007; Kim et al. 2007). The Mie calculations have been preferred in our case because there are still major uncertainties about the characteristics of the particle size distributions, especially of the statistics of small ice crystals (e.g., McFarquhar et al. 2007), and about the most representative ice habit, shape, and density of ice particles in ice clouds, which all impact complex calculations probably as much as simple Mie calculations. We have also repeated these calculations using the Brown and Francis (1995) density-diameter relationship, which is widely assumed in ice cloud retrieval techniques (e.g., Wang and Sassen 2002; Tinel et al. 2005; Hogan et al. 2006; Protat et al. 2007), but this did not change the results significantly. We have then fitted power-law relationships [assuming $Z_{95 \mathrm{GHz}}(\mathrm{dBZ})-Z_{35 \mathrm{GHz}}(\mathrm{dBZ})=$ $a Z_{35 \mathrm{GHz}}(\mathrm{dBZ})^{b}$, with $a$ and $b$ retrieved using a least squares fit] from pairs of reflectivities, which we have then used to convert a reflectivity at one frequency to the other. The result of this is given in Fig. 9 and will be evaluated further in section 5 using the three radar measurements at three wavelengths around Darwin. Obviously, it is expected that the errors are much larger when trying to convert reflectivities from 5 to $95 \mathrm{GHz}$ than when converting from 35 to $95 \mathrm{GHz}$.

\section{c. Statistical comparison of Cloudsat and ground-based radar basic cloud properties}

Figures 10-15 compare the reflectivities and cloud morphological characteristics as derived from the tropical and midlatitude ground-based observations of ice clouds and from the surrounding Cloudsat observations. In all plots, Cloudsat-derived statistics are displayed in black, whereas the statistics derived from the groundbased radars are displayed in gray.

For the tropical sites, the most exact comparison should be at Niamey (Fig. 10) because here both radars are at the same frequency $(95 \mathrm{GHz})$. Apart from a slightly noisier PDF for Cloudsat attributable to a smaller spaceborne sample, the agreement is excellent, with very similar highly skewed distributions and similar widths. It also appears that the Cloudsat PDFs are significantly 

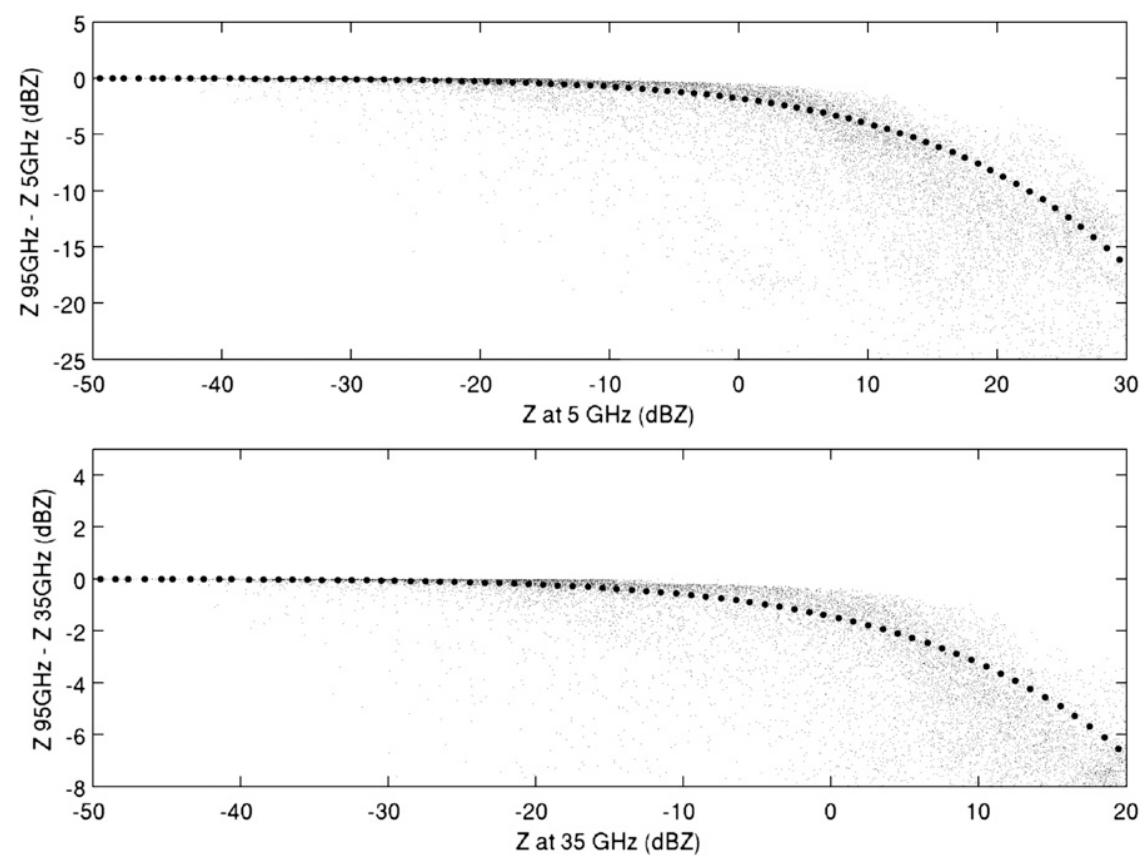

FIG. 9. Reflectivity differences at different wavelengths computed from in situ microphysical measurements of ice particle size distributions. The (top) $95-5-\mathrm{GHz}$ and (bottom) $95-35-\mathrm{GHz}$ reflectivity differences in $\mathrm{dBZ}$ as functions of the reflectivity at 5 and $35 \mathrm{GHz}$, respectively. The small dots are individual estimates and the large dots are from a least squares fit to the individual points (see text).

noisier. The mean vertical profiles of reflectivity (Fig. 10e) are also in relatively good agreement, with a peak reflectivity at approximately the same height and differences generally smaller than $2-3 \mathrm{~dB}$. The weightedmean difference (calculated from the mean vertical profile of reflectivity and the number of points per height slab) is $-0.8 \mathrm{~dB}$. However, Cloudsat reflectivities tend to be higher above $12-\mathrm{km}$ height (up to $1-2 \mathrm{dBZ}$ ) and lower below $12 \mathrm{~km}$ (by up to 3-4 dBZ). Restricting the comparison to $\pm 1 \mathrm{~h}$ seems to modify the structure of the mean vertical profile, with a peak reflectivity at a lower height for the ground-based observations but smaller differences in the lower part of the profile. It is difficult to assess whether this is due to insufficient statistics when using $\pm 1 \mathrm{~h}$ around the overpass time, but it seems to degrade the agreement of the peak reflectivity altitude, which could be an indication that this is the case. The weighted-mean difference for the \pm 1 -h time-lag profile is $0.3 \mathrm{~dB}$. These are small differences when considering all the possible sources of error included in this exercise (calibration accuracy of the ground-based radar, errors in the gaseous attenuation correction, different viewing geometry, etc.). This small number has provided a motivation to see how variable this number was when using other radars at other sites. The PDFs of cloud-base height, cloud-top height, and cloud thickness are also found to be in very good agreement, with a very similar bimodal distribution of cloud-base and cloud-top heights peaking at approximately the same heights (to within $1 \mathrm{~km}$ ). This indicates that there is no particular geolocation problem with the Cloudsat observations (especially in the vertical). The cloud thickness PDFs are also very similar, with exactly the same exponential decrease in the probability of having thick ice clouds. It has to be remembered here that precipitating ice in the upper part of convective systems has been removed from the statistics, hence the lack of significant probability of thick ice clouds.

Similar plots are shown for the Darwin site using the ground-based MMCR (not converted to $95 \mathrm{GHz}$ ) in Fig. 11. The agreement is again very good, with the Cloudsat PDFs again being noisier than the ground-based ones (Figs. 11a-d). The mean vertical profiles of reflectivity also show some differences of the same magnitude as over Niamey (Fig. 11e), but of opposite sign with respect to Fig. 10 and with slightly larger Cloudsat reflectivities below 10-km height and slightly smaller Cloudsat reflectivities above $10 \mathrm{~km}$. This seems to indicate that these differences are due to the fact that the statistics are not derived from exactly the same cloud samples. The weighted-mean difference over Darwin is $-0.6 \mathrm{~dB}$ without any attempt to convert the Darwin MMCR 

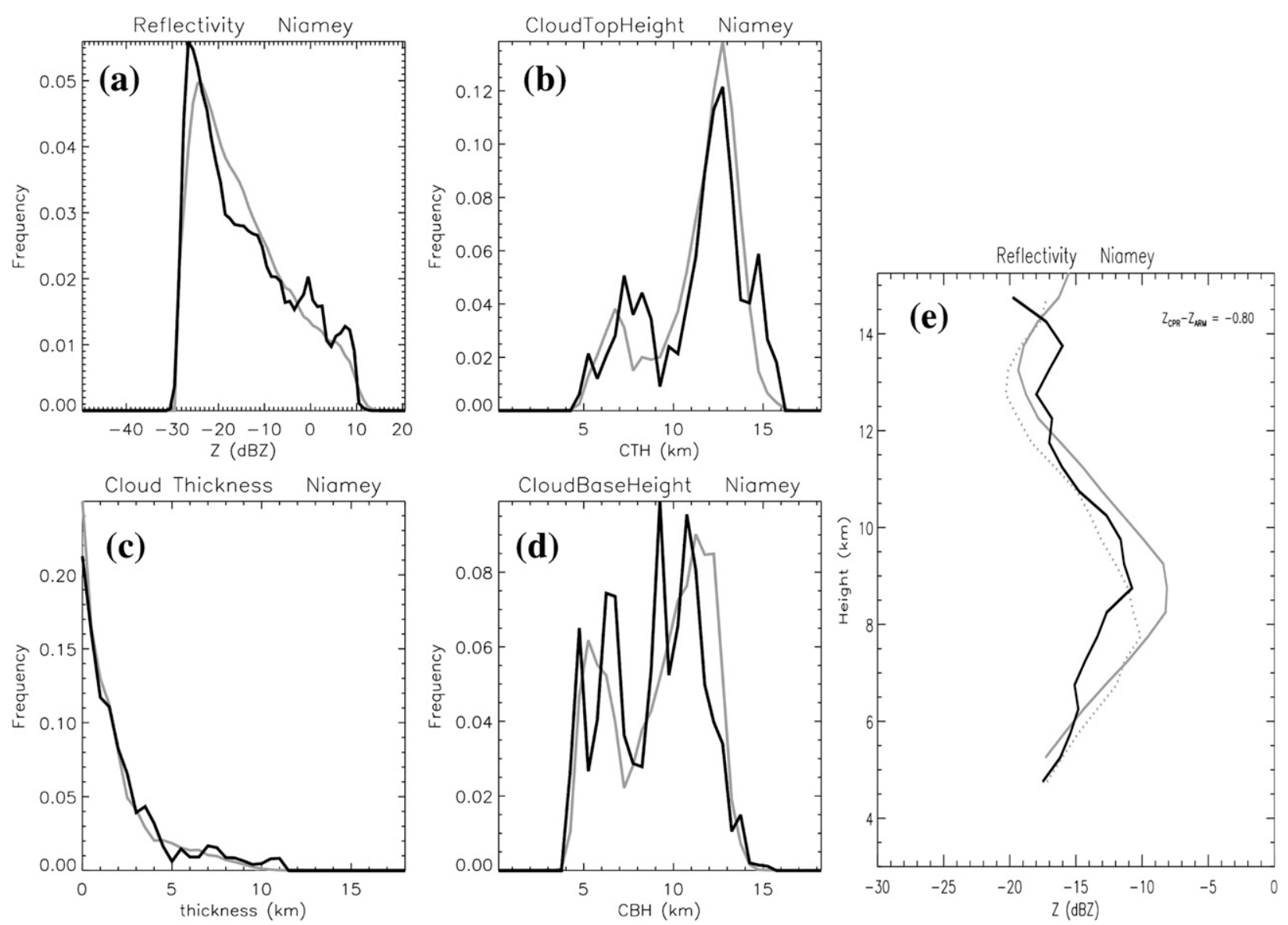

FIG. 10. Statistical comparisons over the Niamey ARM mobile facility between ground-based-derived (gray) and Cloudsat-derived (black) ice cloud morphology: PDFs of (a) radar reflectivity, (b) cloud-top height, (c) cloud thickness, (d) cloud-base height, and (e) mean vertical profile of radar reflectivity. The dotted curve on the mean vertical profile in (e) is for when a \pm 1 -h time window around the Cloudsat overpass time is used to bin the ground-based observations.

reflectivities at the frequency of Cloudsat, as was found using the Niamey observations. When considering a \pm 1 -h time lag around the overpass time, this number remains roughly unchanged $(-0.5 \mathrm{~dB})$. However, when converting the Darwin MMCR reflectivities to $95 \mathrm{GHz}$, the weighted-mean difference is $+0.1 \mathrm{~dB}$ (same number when a \pm 1 -h time lag is considered). It is also observed that the cloud morphology as derived from both radars is very similar. Another way of looking at the differences between Cloudsat and the ground-based radars is to build up joint reflectivity-height histograms. This is shown for Niamey and Darwin in Fig. 12. From Fig. 12, it appears again very clearly that the Cloudsat statistics are much noisier than the ground-based observations with some transient features not included in the groundbased statistics, but it is also clear that the main features derived from the ground-based statistics are also found in the spaceborne statistics, such as the location and extent of the peak reflectivities, some secondary max- ima around $7 \mathrm{~km}$ at Darwin and 6-7 km at Niamey, and width of the reflectivity distributions at different heights. Overall, again, the agreement is very good, although it is not really possible to assess unambiguously from these joint histograms as to which differences are simply due to different cloud statistics and which are potentially due to problems with Cloudsat. Therefore, in what follows, we do not interpret such joint histograms further.

For the midlatitude sites, the comparisons that should be in best agreement are those with the RASTA radar at the SIRTA site in Palaiseau (Fig. 13) and the WACR radar during COPS (Fig. 14) because all radars operate at the same frequency $(95 \mathrm{GHz})$, which was the case of Niamey in the tropics. The shorter period for the comparisons between RASTA and Cloudsat is due to the fact that the ground-based RASTA radar at SIRTA is the same as that used in an airborne configuration during AMMA and CIRCLE-2. The COPS dataset is of the same duration as for the tropical sites. The comparisons 

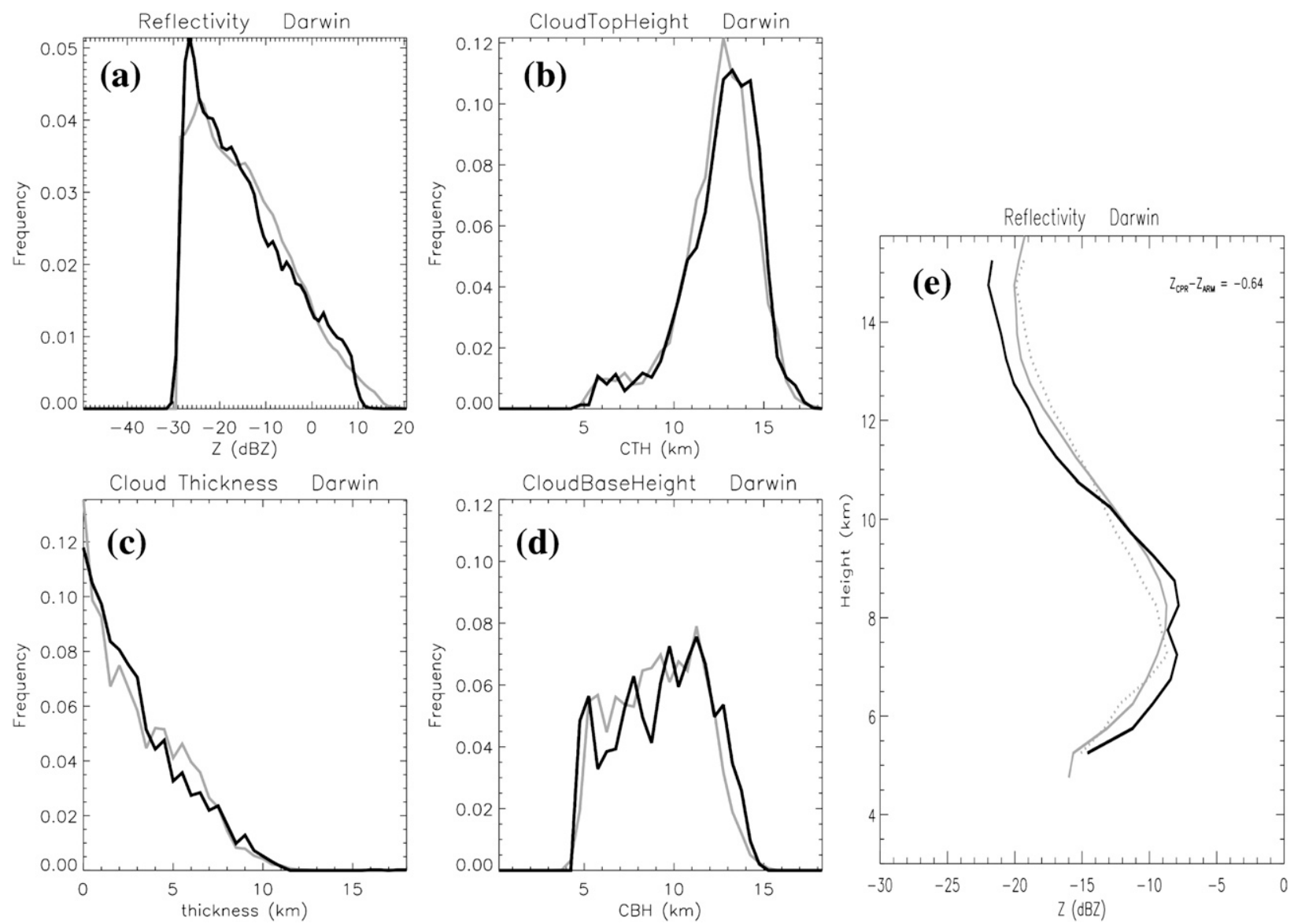

FIG. 11. As in Fig. 10, but with the original 35-GHz MMCR observations over the Darwin ARM site.

at Lindenberg (Fig. 15) are equivalent to the Darwin comparisons in the tropics because the Lindenberg radar operates at $35 \mathrm{GHz}$, and the reflectivities are then converted to $95 \mathrm{GHz}$ using the relationships derived from Fig. 9. The main difference of this radar with respect to all others used in this study is that it uses a magnetron as a transmitting source and not a klystron, which allows for larger power outputs (and therefore higher sensitivity) but a somewhat less accurate control of transmitted pulse characteristics (magnitude and phase).

The results over the Palaiseau and COPS sites (Figs. $13,14)$ are very similar to what has been obtained in the tropics, with very similar reflectivity and basic cloud property statistics. The joint reflectivity-height histograms also indicate very good agreement (not shown) as in the tropics. The weighted-mean differences over Palaiseau and COPS are +0.0 and $-0.70 \mathrm{~dB}$, respectively. With a \pm 1 -h time lag, these differences become -0.2 and $-0.4 \mathrm{~dB}$, respectively. It is noteworthy that the same WACR radar is used during COPS and at Niamey and that the results found for the differences with Cloudsat are quite similar for the two sites $(-0.80 \mathrm{~dB}$ for
Niamey and $-0.70 \mathrm{~dB}$ for COPS). This can viewed either as very lucky or as an indirect validation of the robustness of our statistical approach. The results for Lindenberg are significantly different (Fig. 15). Although the PDFs of reflectivity and basic cloud properties agree fairly well as over the other sites, the mean vertical profile exhibits a clear systematic shift between Cloudsat and the Lindenberg radar, with Cloudsat reflectivities being systematically larger than the ground-based ones. The weighted-mean difference without reflectivity conversion and when no time lag is applied is $+1.3 \mathrm{~dB}$. It is about the same with $\pm 1 \mathrm{~h}$ around the overpass, and it reaches $+1.9 \mathrm{~dB}$ when Lindenberg reflectivities are converted at $95 \mathrm{GHz}$. Interestingly, during the COPS experiment, MIRA and WACR have been compared using detailed case studies (Handwerker and Miller 2008) showing a 3-dB difference between these two radars (WACR being higher than the Lindenberg radar). It is significant to see here that when using Cloudsat as a reference (just for this calculation) we are almost able to reproduce this difference with our statistics $(1.9+0.7=$ $2.6 \mathrm{~dB}$ ), which is a very good indirect overall validation 

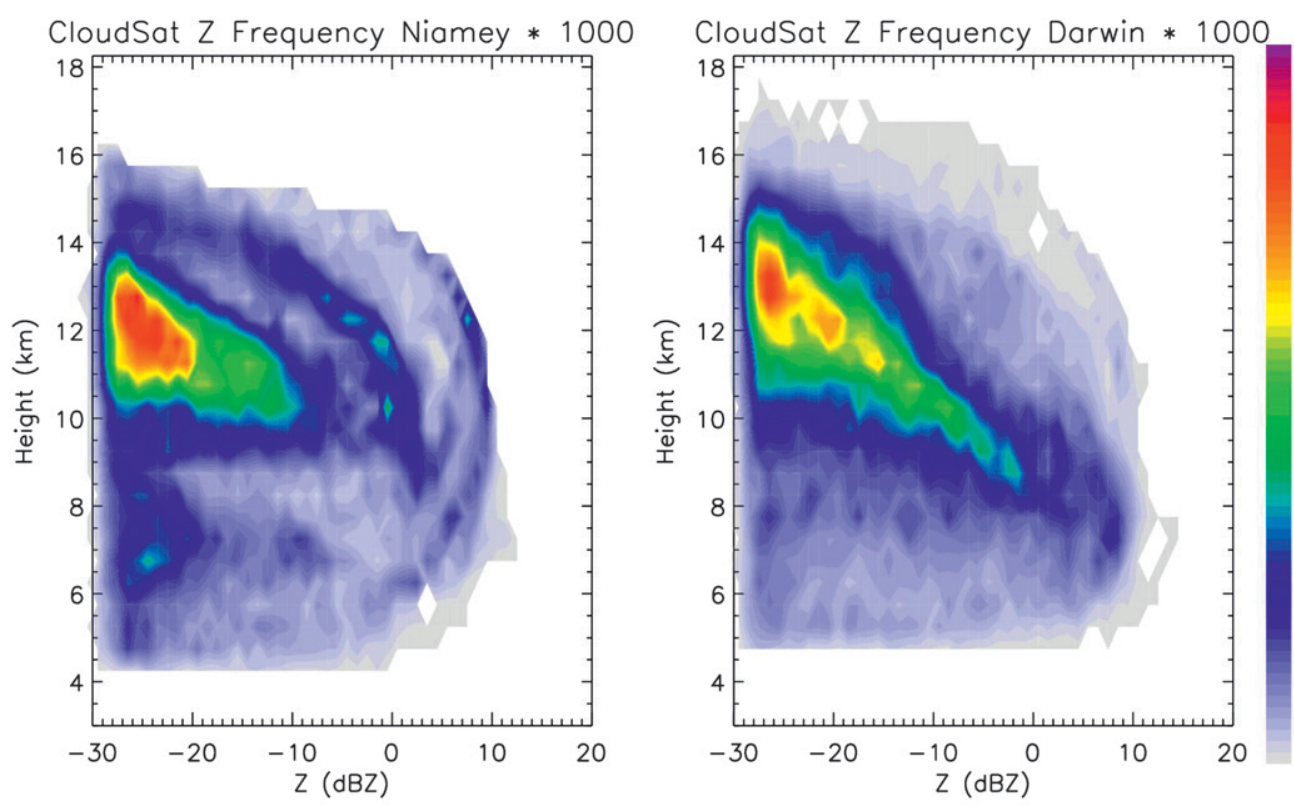

6.

5.

4.

3.

1.

0.
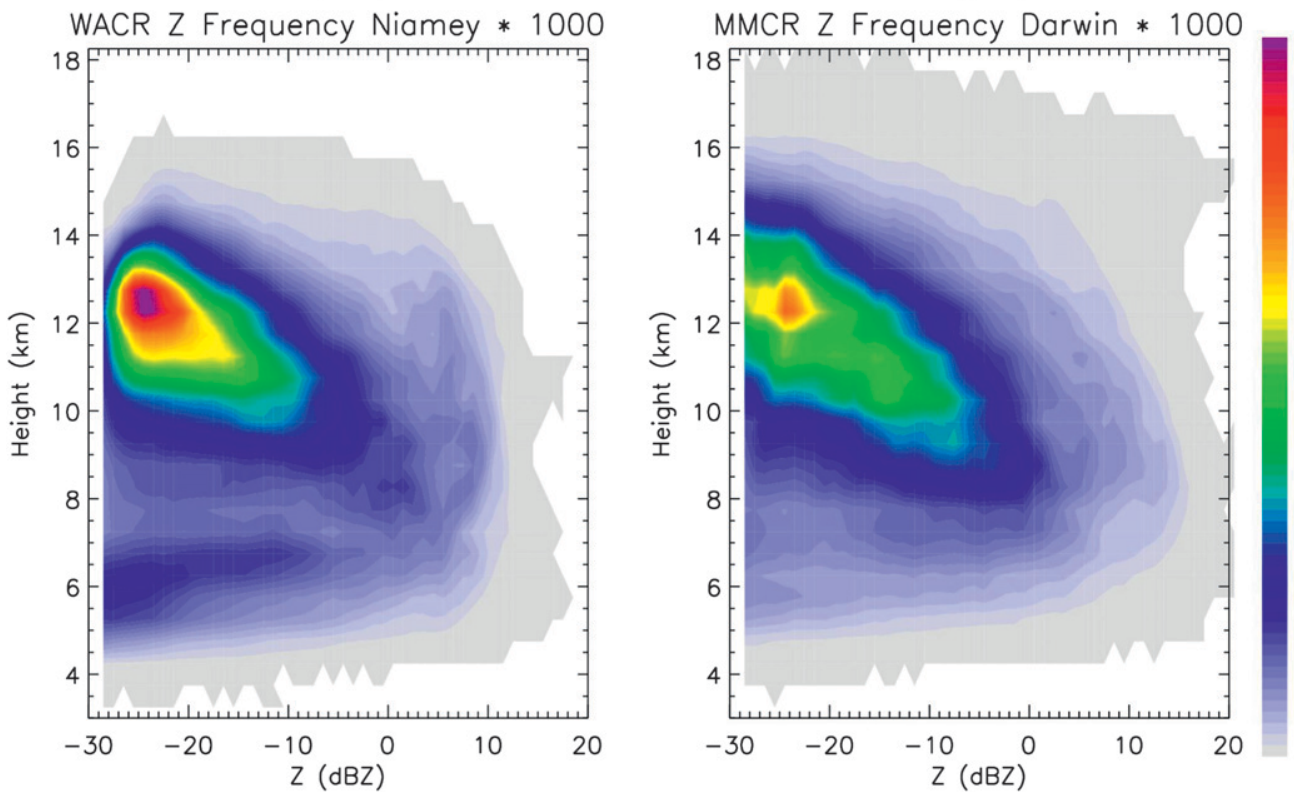

6.

5.

4.

3.

1.

0.

FIG. 12. Comparison of joint height-reflectivity histograms derived from (top) the Cloudsat radar and the ground-based (bottom left) Niamey WACR and (bottom right) Darwin 35-GHz MMCR.

of the statistical approach. We believe that, because the four comparisons over the four other sites agree to within $1 \mathrm{~dB}$, this is indirect proof that the calibration of the Lindenberg radar may be low by around $2 \mathrm{~dB}$. This is most likely due to the fact that the calibration figure has been derived from a budget of internal gains and losses but no comparisons using reference targets or ocean backscatter returns.

As a summary, if we assume that the calibration of the Lindenberg radar is slightly low, then the weighted-mean difference between Cloudsat and the other ground-based radars, $Z_{\text {Cloudsat }}-Z_{\text {Ground }}$, ranges from -0.8 to $+0.1 \mathrm{~dB}$ if no time lag is considered and from -0.4 to $+0.3 \mathrm{~dB}$ when a \pm 1 -h time lag around the Cloudsat overpass is considered. These numbers are unexpectedly small (and consistently small over the different sites), when considering the possible sources of errors discussed previously. These estimates are also in good agreement with the airborne comparisons, which can be considered as a cross-validation of the two approaches.

This study suggests that the Cloudsat reflectivities are well calibrated. An implication of this is that these 

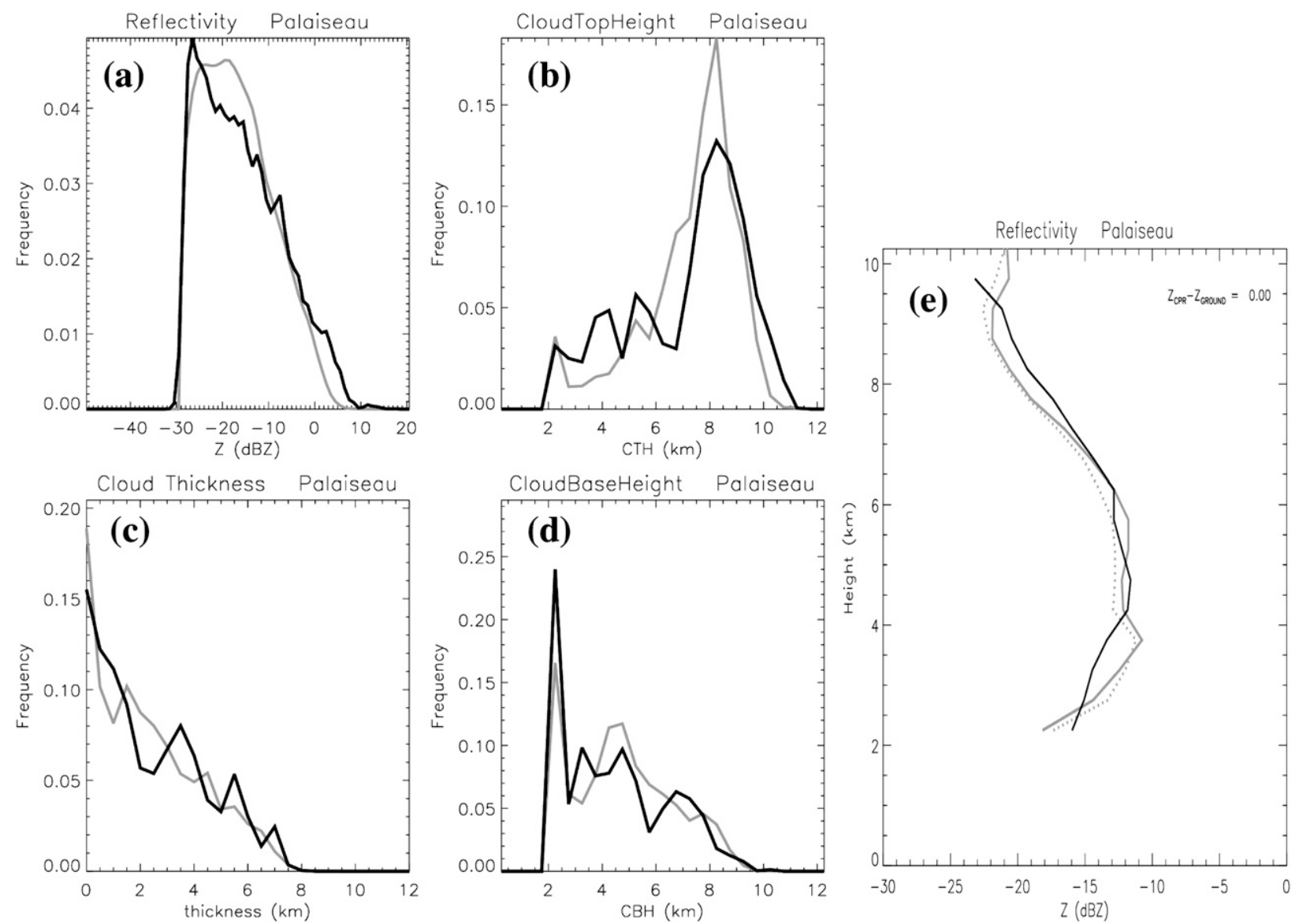

FIG. 13. As in Fig. 10, but over the SIRTA observatory in Palaiseau.

Cloudsat reflectivities can also be exploited quantitatively using the same statistical approach as that developed in this section to calibrate or check calibration of any radar in the world operating at the same frequency, and even with some caution any radar at other frequencies provided that reflectivities are either converted to $95 \mathrm{GHz}$ or compared in the so-called Rayleigh-scattering domain of the Cloudsat reflectivities. The previous Lindenberg results are a good illustration of this point.

\section{Assessment of the Cloudsat convective ice reflectivities for quantitative studies}

A potential advantage of Cloudsat over the groundbased 35- and 95-GHz radars for the characterization of convective ice is that it provides sampling of the ice part of convective storms from the top down and therefore does not experience attenuation by the liquid part of the convective storms (typically located below the $0^{\circ} \mathrm{C}$ isotherm altitude). Cloudsat does therefore provide a unique view of tropical convective ice at millimeter wavelength and at global scale. However the Cloudsat observations can be contaminated by three effects: attenuation by supercooled liquid water, attenuation by large ice particles, and multiple scattering in the Cloudsat radar beam.

Supercooled liquid water is very commonly found in these convective storms because of the vigorous updrafts carrying substantial amounts of liquid water above the melting layer (e.g., Stith et al. 2002; Rosenfeld et al. 2006; Kingsmill et al. 2004; Fiorino and Smith 2006). This supercooled liquid water will produce attenuation of Cloudsat. The literature remains relatively poor regarding the presence and amount of supercooled water and maximum height at which it can be encountered in tropical convective storms. In deep convective cores, a single study by Rosenfeld et al. (2006) and early results presented in Rosenfeld and Woodley (2000) document very high amounts of supercooled liquid water up to very high altitudes $\left(-38^{\circ} \mathrm{C}\right.$ isotherm altitude). In tropical stratiform anvils, some studies indicate the presence of significant amounts of supercooled liquid water mostly below the $-12^{\circ}$ to $-18^{\circ} \mathrm{C}$ isotherm altitudes (Stith et al. 2002), whereas others document regular occurrences of 

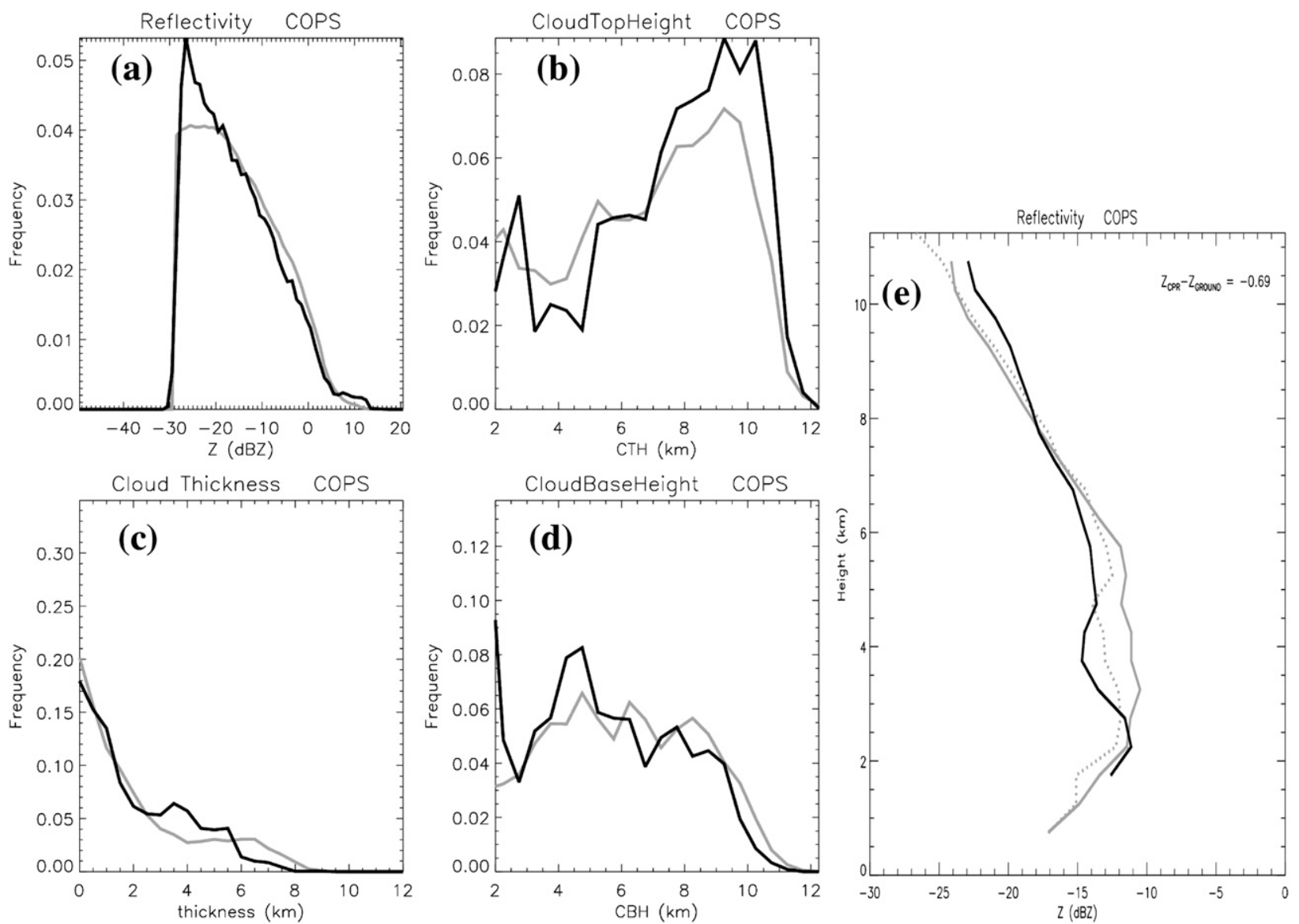

FIG. 14. As in Fig. 10, but over the COPS ARM mobile facility site.

supercooled liquid water up to a $9.5-\mathrm{km}$ altitude in the tropics (Fiorino and Smith 2006; Kingsmill et al. 2004).

Mesoscale convective storms also produce a variety of ice particles in terms of shape, orientation, density, size, and degree of riming. There are not many studies that have attempted to estimate the attenuation of millimeterwavelength radars by precipitating ice resulting from the complexity of ice microphysics (Lhermitte 1990). Li et al. (2001) documented values of around $0.38 \mathrm{~dB} \mathrm{~km}^{-1}$ using collocated ground-based and airborne $95-\mathrm{GHz}$ cloud radar observations in a thick midlatitude stratiform anvil cloud. Matrosov (2007) estimated attenuation of up to $0.4 \mathrm{~dB} \mathrm{~km}^{-1}$ in heavy snowfall rates and mentioned that for wet and/or rimed snow (as can be found in deep convective storms) this attenuation could be significantly larger. From combined in situ and dualwavelength radar observations in the tropics, there is also some very recent evidence of attenuation by graupel reaching as high as $4-5 \mathrm{~dB} \mathrm{~km}^{-1}$ (G. and A. Heymsfield 2008, personal communication).

Finally, multiple scattering in the Cloudsat beam will also tend to balance in part the attenuation by increasing
95-GHz reflectivity (Marzano et al. 2003; Battaglia et al. 2005; Kobayashi et al. 2005) but to a degree and vertical extent that is still largely unknown (e.g., Bouniol et al. 2008). Battaglia et al. (2007) documented multiple scattering effects as high as $10 \mathrm{~dB}$ at $3 \mathrm{~km}$ above the melting layer of a deep snow storm responsible for only moderate rainfall rates at ground. A first observational estimate in the ice part of tropical convection has been obtained by Bouniol et al. (2008), who reported a value of at least 2.5 $\mathrm{dB}$ at $8.5-\mathrm{km}$ height in the anvil of a West African mesoscale convective system sampled during AMMA.

In the context described previously, it is obviously crucial to come up with estimates of how large these combined effects are in a statistical sense and at which height these effects really contaminate the Cloudsat convective ice profiles before using such profiles for quantitative studies. The following analysis is a first attempt to estimate at a single location how large these effects are and at which heights.

Near the Darwin ARM site, the Australian Bureau of Meteorology operates the CPOL scanning dual-polarization research radar (Keenan et al. 1998) continuously during the 

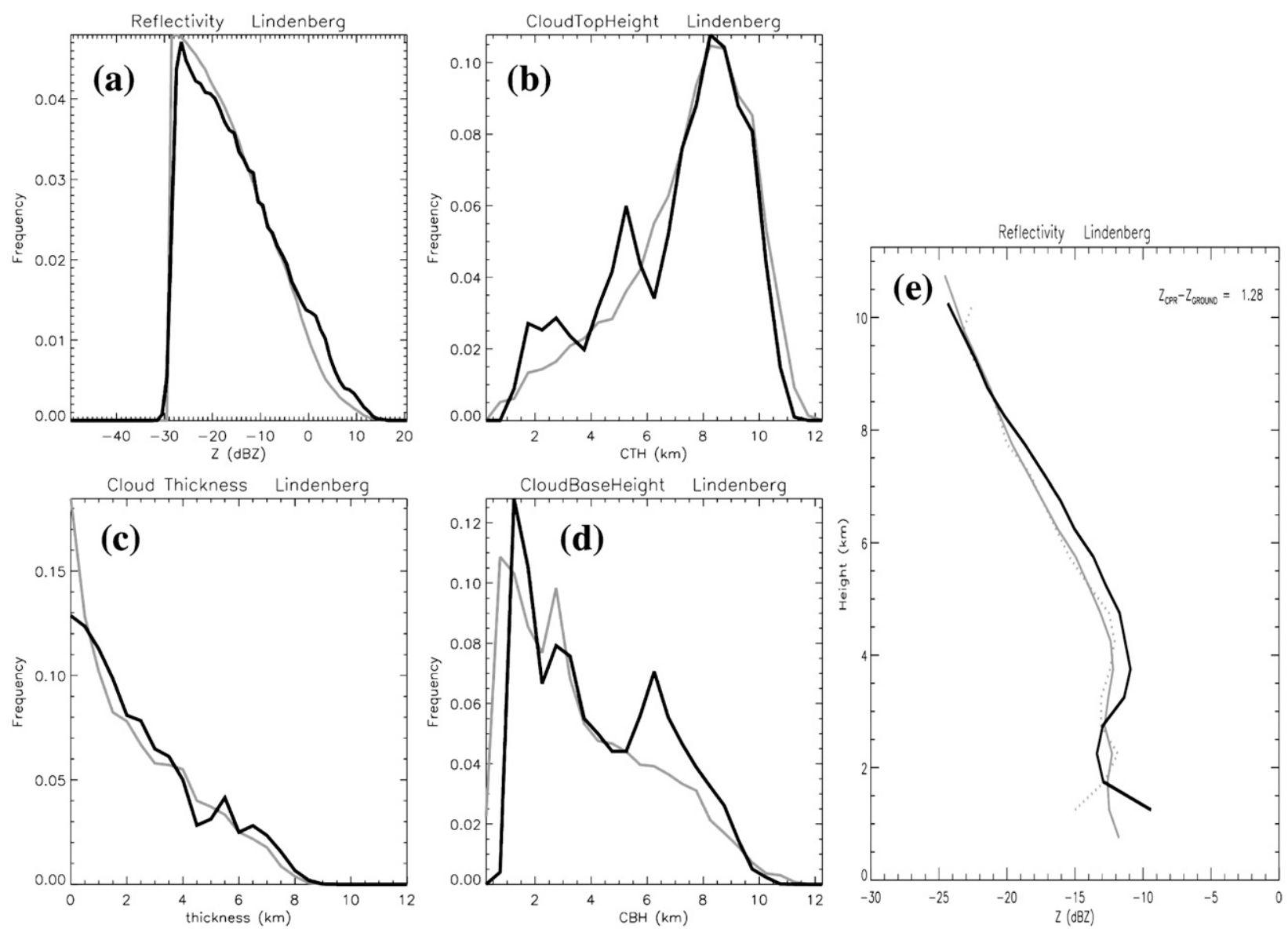

FIG. 15. As in Fig. 10, but with the original 35-GHz MIRA radar observations over Lindenberg.

wet season, which provides attenuation-corrected (using the method described in Bringi et al. 2001) and calibrated observations of the convective ice in this area (10-min volumetric scans, RHIs over the Darwin ARM site every $10 \mathrm{~min}$, and vertically pointing observations every $10 \mathrm{~min}$ ). However, this radar operates at a 5-GHz frequency, so further comparisons with Cloudsat would require a reflectivity conversion from 5 to $95 \mathrm{GHz}$ such as that proposed in Fig. 9. Corrections are much larger than when converting from 35 to $95 \mathrm{GHz}$ (it reaches around $15 \mathrm{dBZ}$ for a $30-\mathrm{dBZ}$ reflectivity at $5 \mathrm{GHz}$ ), so we do expect errors from this conversion. To estimate this error, the ice cloud reflectivity profiles from Cloudsat that have been validated in section 4 by using the Darwin MMCR radar reflectivities are considered again. These Cloudsat profiles have been degraded to the CPOL sensitivity ( $-21 \mathrm{~dB} Z$ at $10-\mathrm{km}$ range) and compared to the reflectivity statistics derived from the CPOL profiles collected during the same period (December 2006-April 2007). This comparison is shown in Fig. 16, and the vertical profiles that had been obtained with MMCR (at Cloudsat sensitivity) and Cloudsat are also reproduced as dashed lines for the sake of comparison. As can be clearly seen from Fig. 16, the reflectivity conversion from 5 to $95 \mathrm{GHz}$ seems to work very well in a statistical sense because the agreement reached with the Cloudsat mean ice cloud reflectivity profile is extremely good (and comparable to the agreement reached between MMCR and Cloudsat), with a weighted-mean difference between Cloudsat and CPOL of $+0.3 \mathrm{~dB}$, which agrees well with the difference found with the Darwin MMCR in section $4(+0.1 \mathrm{~dB})$. The implication of this is that we can now use the CPOL convective ice mean profiles of $95-\mathrm{GHz}$ reflectivities as a reference for the statistical evaluation of the Cloudsat reflectivities in convective ice. We have considered again the same period (December 2006-April 2007) for the analysis and repeated the same statistical analysis as we did for the ice cloud profiles. Also, as for the ice cloud analysis, we have considered a $200-\mathrm{km}$ radius around the Darwin sites, and we have not used any maximum time lag around the Cloudsat overpass time. These mean vertical profiles are shown in Fig. 17. The comparison is not shown above a $13-\mathrm{km}$ height because of the lack of a 


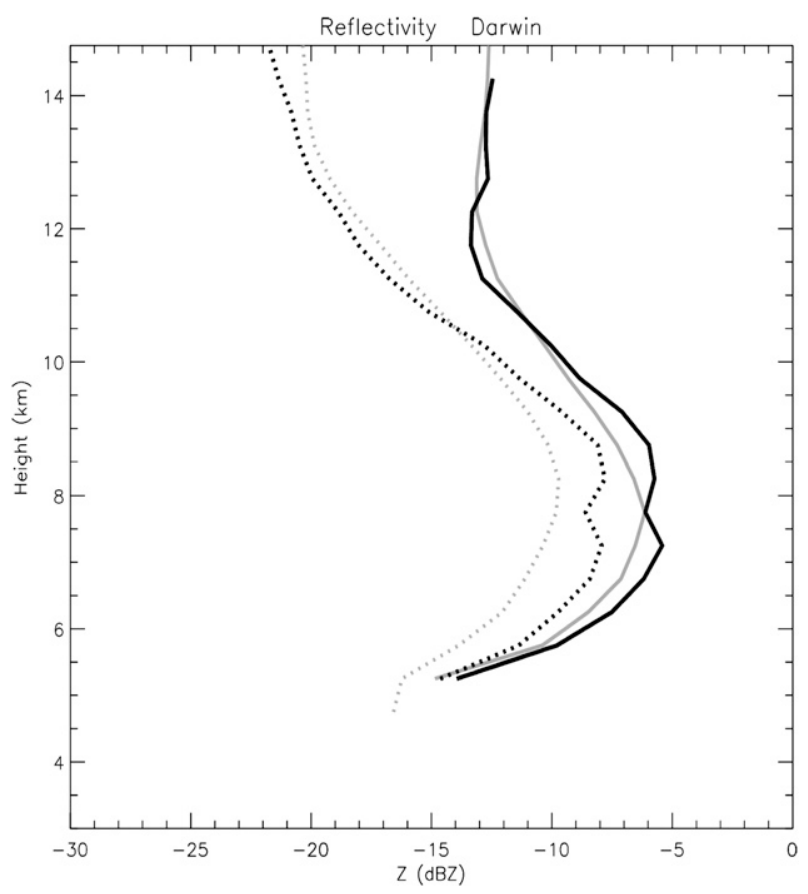

FIG. 16. Mean vertical profiles of ice cloud reflectivity over Darwin from CPOL converted at $95-\mathrm{GHz}$ frequency (solid gray line), Cloudsat at CPOL sensitivity (solid black line), Cloudsat (dotted black line), and MMCR at Cloudsat sensitivity and converted to the $95-\mathrm{GHz}$ frequency (dotted gray line).

sufficient amount of data in the CPOL statistics above that height. The agreement between the two profiles is very good (within a $\mathrm{dB}$ ) from a $13-\mathrm{km}$ height down to approximately a 9-km height (which corresponds to $-26^{\circ} \mathrm{C}$ if we use a lapse rate of $-6.5^{\circ} \mathrm{C} \mathrm{km}^{-1}$ and a $0^{\circ} \mathrm{C}$ isotherm altitude of 5-km height) and the vertical gradient of reflectivity is very similar. From a $9-\mathrm{km}$ height down to the melting layer, the slope of the Cloudsat profile clearly changes, whereas the CPOL reflectivities continue to increase at approximately the same rate as above 9-km height. From 9- to 7-km height, the rate of reflectivity difference is about $1 \mathrm{~dB} \mathrm{~km}^{-1}$, then increasing strongly from 7 to $5.5 \mathrm{~km}$ (around $-2 \mathrm{~dB}$ $\mathrm{km}^{-1}$ ). The difference between Cloudsat and CPOL reaches a maximum of $-5.5 \mathrm{~dB}$ at a $5.5-\mathrm{km}$ height, which is large and cannot be neglected. As discussed previously, this reduction in mean Cloudsat reflectivities can be due to attenuation by supercooled liquid water carried aloft by the strong convective updrafts and to attenuation by very dense ice particles (ice aggregates and graupel are expected at this height in convective storms). It must be noted also that the additional effect of multiple scattering within the Cloudsat beam tends to increase reflectivity (opposing the effect of attenuation), which implies that attenuation is even larger than the difference found in Fig. 17 between the Cloudsat and

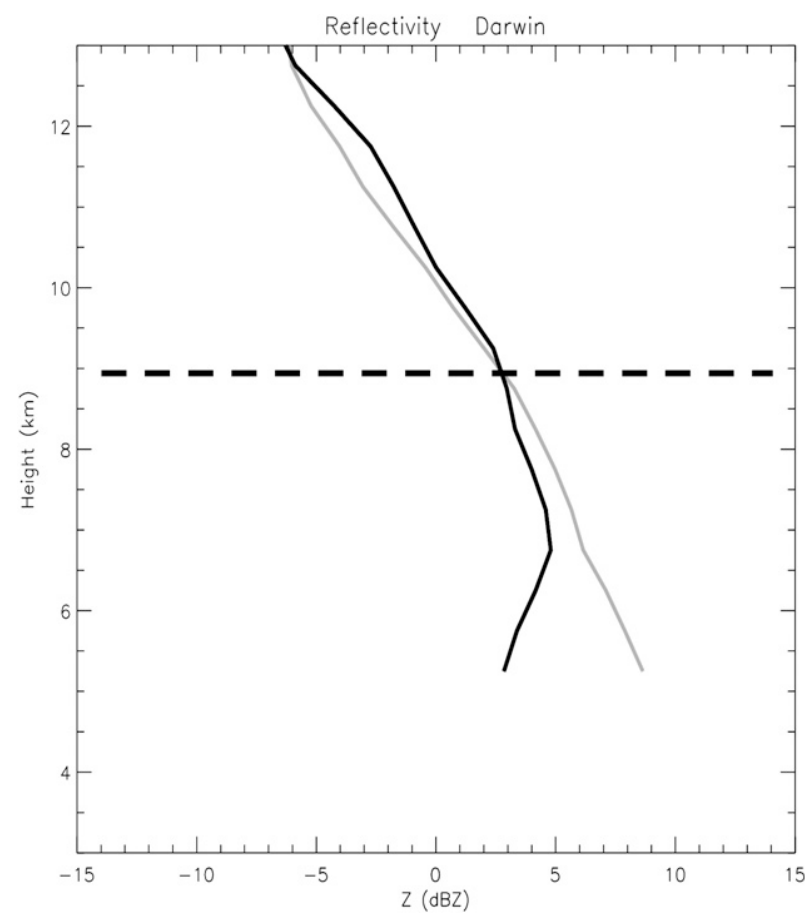

FIG. 17. Mean vertical profiles of convective ice reflectivity over Darwin from CPOL converted to the $95-\mathrm{GHz}$ frequency (solid gray line) and Cloudsat to CPOL sensitivity (solid black line).

CPOL profiles. The respective magnitude of these three effects cannot be estimated using our statistical approach; however, as seen in Fig. 17, the cumulative effect is large.

Whether the previous results are representative of the statistics of all deep convective storms in the tropics is difficult to assess with our currently limited knowledge of the variability of the convective ice properties along the tropical belt (e.g., Protat et al. 2009). On one hand, our statistical results are derived from a specific region of the tropics and the results may be representative of this region only. On the other hand, Darwin is located in a region typical of monsoonal deep convective storms (May et al. 2008), storms that are known to produce most of the convective ice in the tropics. More studies are clearly required, but from this first statistical study we suggest that the Cloudsat profiles in convective ice need to be corrected for attenuation and multiple scattering prior to their quantitative use.

\section{Conclusions}

A quantitative assessment of Cloudsat reflectivities and basic ice cloud properties (cloud base, top, and thickness) has been conducted in the present paper from both airborne and ground-based observations. The rationale for using both airborne and ground-based observations is that airborne observations allow direct 
comparisons on a limited number of ocean return and cloud samples if good collocation in time and space is achieved and a proper averaging of the airborne data is done, whereas the ground-based observations allow for statistical comparisons on much longer time series but with different assumptions.

To evaluate the Cloudsat radar observations, we have used observations from two experiments in 2006-07: AMMA in West Africa and CIRCLE-2 in Western Europe. Direct comparisons of the ocean backscatter measured by the airborne RASTA cloud radar and Cloudsat during AMMA and CIRCLE-2 were investigated first. When taking all the $\sigma_{0}$ measurements together, the Cloudsat $\sigma_{0}$ is an average of $0.4 \mathrm{~dB}$ larger than the RASTA $\sigma_{0}$. The standard deviation of this difference is $1 \mathrm{~dB}$. These numbers are fairly small. This 0.4- $\mathrm{dB}$ mean difference is smaller than the expected accuracy of the calibration of RASTA (around $1 \mathrm{~dB}$ ). Direct comparisons using ice clouds as targets in three CIRCLE-2 underflights of the Cloudsat track indicate that Cloudsat measures reflectivities $1 \mathrm{~dB}$ higher than the airborne cloud radar. Considering again that the calibration accuracy of the airborne radar is about $1 \mathrm{~dB}$, we conclude that the reflectivities agree within the expected RASTA calibration uncertainties. The standard deviation of the difference for the comparisons using ice clouds is however significantly larger $(2-3 \mathrm{~dB})$ than that found when using ocean backscatter $(1 \mathrm{~dB})$. This indicates that the ocean surface was, in this case, a better target than ice clouds for this spaceborne radar assessment. This may however not always be the case, especially in regions of large variability of the surface wind speed and direction, which can produce a large variability of the ocean backscatter.

Five ground-based datasets have then been used for a statistical evaluation of the Cloudsat reflectivities and basic cloud properties. Only the ice cloud profiles have been retained for the comparison to avoid any difference resulting from differential attenuation between the ground-based and spaceborne radars. For these comparisons, we needed to assume that the statistical properties of ice clouds were reasonably invariant within a given range from the ground-based site location. Sensitivity tests have shown that a $200-\mathrm{km}$ radius was suitable for the length of our observational periods (about 6 months over each site). The time difference also plays a role, in some cases, on the statistics, but generally this effect, which is a result of the diurnal variability of the ice cloud properties, is smaller than the effect of the chosen radius. Different time intervals have therefore been considered around the satellite overpass to provide an error bar associated with this effect. From these comparisons, we find that the PDFs of cloud properties are generally in excellent agreement over all the sites. The weighted-mean difference $Z_{\text {Cloudsat }}-Z_{\text {Ground }}$ ranges from -0.4 to $+0.3 \mathrm{~dB}$ when a \pm 1 -h time lag around the Cloudsat overpass is considered. The only departure is at the Lindenberg site, but this is probably due to a slight undercalibration of the Lindenberg radar. These numbers are unexpectedly small when considering the possible sources of errors, and they are also consistent with the numbers found during the airborne assessment.

Finally, we have used the opportunity offered by the Darwin CPOL radar to evaluate the tropical convective ice profiles measured by Cloudsat as well. We show that the Cloudsat convective ice profiles can be used down to approximately a 9-km height (or $4 \mathrm{~km}$ above the melting layer) without attenuation correction over Darwin. This study, however, suggests that the Cloudsat profiles in convective ice need to be corrected for attenuation by supercooled liquid water and ice aggregates/graupel particles and multiple scattering prior to their quantitative use.

Acknowledgments. This work has been partly supported by the U.S. Department of Energy Atmospheric Radiation Measurement Program (ARM) and the French Space Agency [Centre National d'Études Spatiales (CNES)]. The Niamey AMF, COPS AMF, and Darwin radar data were obtained from the ARM archive. The NASA Cloudsat CPR data and products were obtained from the Cloudsat Data Processing Center run by the Cooperative Institute for Research in the Atmosphere (CIRA). The SIRTA and Lindenberg observatories are also acknowledged for the provision of the RASTA and MIRA Doppler cloud radar observations used in this study. Based on a French initiative, AMMA was built by an international scientific group and is currently funded by a large number of agencies, especially from France, the United Kingdom, the United States, and Africa. Detailed information on scientific coordination and funding is available on the AMMA International Web site (available online at http:// www.amma-international.org). We also wish to thank our DLR colleagues and particularly Andreas Minikin for the organization of the CIRCLE- 2 coordinated flights and weather forecasts; Simone Tanelli from NASA JPL for the orbital predictions during AMMA and CIRCLE-2 and for interesting discussion about airborne/spaceborne comparisons and calibration; Michael Whimpey from CAWCR and V. Bringi and M. Thurai from Colorado State University for the production of the attenuationcorrected CPOL observations used in this study; and, of course, the RALI engineers (Jean-Paul Vinson and Noel Grand) for their impressive dedication during the field experiments. 


\section{REFERENCES}

Battaglia, A., M. O. Ajewole, and C. Simmer, 2005: Multiple scattering effects due to hydrometeors on precipitation radar systems. Geophys. Res. Lett., 32, L19801, doi:10.1029/ 2005GL023810.

,-- , and -2007 : Evaluation of radar multiple scattering effects in Cloudsat configuration. Atmos. Chem. Phys., 7, 1719-1730.

Bouniol, D., A. Protat, A. Plana-Fattori, M. Giraud, J.-P. Vinson, and N. Grand, 2008: Comparison of airborne and spaceborne 95-GHz radar reflectivity and evidence of multiple scattering effects in spaceborne measurements. J. Atmos. Oceanic Technol., 25, 1983-1995.

Bringi, V. N., G.-J. Huang, V. Chandrasekar, and T. D. Keenan, 2001: An areal rainfall estimator using differential propagation phase: Evaluation using a C-band radar and a dense gauge network in the tropics. J. Atmos. Oceanic Technol., 18, 1810-1818.

Brown, P. R. A., and P. N. Francis, 1995: Improved measurements of the ice water content in cirrus using a total-water probe. J. Atmos. Oceanic Technol., 12, 410-414.

Cox, C., and W. Munk, 1954: Measurements of the roughness of the sea surface from photographs of the sun's glitter. J. Opt. Soc. Amer., 144, 838-850.

Delanoë, J., and R. J. Hogan, 2008: A variational scheme for retrieving ice cloud properties from combined radar, lidar, and infrared radiometer. J. Geophys. Res., 113, D07204, doi:10.1029/2007JD009000.

— A. Protat, J. Testud, D. Bouniol, A. J. Heymsfield, A. Bansemer, P. R. A. Brown, and R. M. Forbes, 2005: Statistical properties of the normalized ice particle size distribution. J. Geophys. Res., 110, D10201, doi:10.1029/ 2004JD005405.

Donovan, D. P., M. Quante, I. Schlimme, and A. Macke, 2004: Use of equivalent spheres to model the relation between radar reflectivity and optical extinction of ice cloud particles. Appl. Opt., 43, 4929-4940.

Ellingson, R. G., J. Ellis, and S. Fels, 1991: The intercomparison of radiation codes used in climate models: Long wave results. J. Geophys. Res., 96 (D5), 8929-8953.

Fiorino, S. T., and E. A. Smith, 2006: Critical assessment of microphysical assumptions within TRMM radiometer rain profile algorithm using satellite, aircraft, and surface datasets from KWAJEX. J. Appl. Meteor. Climatol., 45, 754-786.

Freilich, M. H., and B. A. Vanhoff, 2003: The relationship between winds, surface roughness, and the radar backscatter at low incidence angles from TRMM precipitation measurements. J. Atmos. Oceanic Technol., 20, 549-562.

Haeffelin, M., and Coauthors, 2005: SIRTA, a ground-based atmospheric observatory for clouds and aerosol research. Ann. Geophys., 23, 253-275.

Handwerker, J., and M. A. Miller, 2008: Intercomparison of measurements obtained by vertically pointing collocated $95 \mathrm{GHz}$ and $35.5 \mathrm{GHz}$ cloud radars. Proc. Fifth European Conference on Radar in Meteorology and Hydrology, Helsinki, Finland, Finish Meteorological Institute, P5.3. [Available online at http://erad2008.fmi.fi/proceedings/extended/erad2008-0124extended.pdf.]

Heymsfield, A. J., A. Bansemer, and C. Twohy, 2007: Refinements to ice particle mass dimensional and terminal velocity relationships for ice clouds. Part I: Temperature dependence. J. Atmos. Sci., 64, 1047-1067.
Hogan, R. J., M. P. Mittermaier, and A. J. Illingworth, 2006: The retrieval of ice water content from radar reflectivity factor and temperature and its use in the evaluation of a mesoscale model. J. Appl. Meteor. Climatol., 45, 301-317.

Illingworth, A. J., and Coauthors, 2007: Cloudnet: Continuous evaluation of cloud profiles in seven operational models using ground-based observations. Bull. Amer. Meteor. Soc., 88, 883-898.

Keenan, T. D., K. Glasson, F. Cummings, T. S. Bird, J. Keeler, and J. Lutz, 1998: The BMRC/NCAR C-band polarimetric (CPOL) radar system. J. Atmos. Oceanic Technol., 15, 871-886.

Kim, M.-J., M. S. Kulie, C. O'Dell, and R. Bennartz, 2007: Scattering of ice particles at microwave frequencies: A physically based parameterization. J. Appl. Meteor. Climatol., 46, 615-633.

Kingsmill, D., and Coauthors, 2004: TRMM common microphysics products: A tool for evaluating spaceborne precipitation retrieval algorithms. J. Appl. Meteor., 43, 1598-1618.

Kobayashi, S., S. Tanelli, and E. Im, 2005: Second-order multiplescattering theory associated with backscattering enhancement for a millimeter wavelength weather radar with a finite beam width. Radio Sci., 40, doi:10.1029/2004RS003219.

Lhermitte, R., 1990: Attenuation and scattering of millimeter wavelength radiation by clouds and precipitation. J. Atmos. Oceanic Technol., 7, 464-479.

Li, L., and Coauthors, 2001: Retrieval of atmospheric attenuation using combined ground-based and airborne $95-\mathrm{GHz}$ cloud radar measurements. J. Atmos. Oceanic Technol., 18, 1345-1353.

- G. M. Heymsfield, L. Tian, and P. E. Racette, 2005: Measurements of ocean surface backscattering using an airborne 95-GHz cloud radar-Implication for calibration of airborne and spaceborne W-band radars. J. Atmos. Oceanic Technol., 22, 1033-1045.

Liebe, H. J., G. A. Hufford, and M. G. Cotton, 1993: Propagation modeling of moist air and suspended water/ice particles below 1000 GHz. Proc. Electromagnetic Wave Propagation Panel Symp., Palma de Mallorca, Spain, Advisory Group for Aerospace Research and Development.

Marzano, F. S., L. Roberti, S. Di Michele, A. Mugnai, and A. Tassa, 2003: Modeling of apparent radar reflectivity due to convective clouds at attenuating wavelengths. Radio Sci., 38, 1002, doi:10.1029/2002RS002613.

Matrosov, S. Y., 2007: Modeling backscatter properties of snowfall at millimeter wavelengths. J. Atmos. Sci., 64, 1727-1736.

May, P. T., J. H. Mather, G. Vaughan, C. Jakob, G. M. McFarquhar, K. N. Bower, and G. G. Mace, 2008: The Tropical Warm Pool International Cloud Experiment. Bull. Amer. Meteor. Soc., 89, 629-645.

McFarquhar, G. M., J. Um, M. Freer, D. Baumgardner, G. L. Kok, and G. Mace, 2007: Importance of small ice crystals to cirrus properties: Observations from the Tropical Warm Pool International Cloud Experiment (TWP-ICE). Geophys. Res. Lett., 34, L13803, doi:10.1029/2007GL029865.

Oguchi, T., 1983: Electromagnetic wave propagation and scattering in rain and other hydrometeors. Proc. IEEE, 71, 1029-1078.

Okamoto, K., T. Kubokawa, A. Tamura, and T. Ushio, 2002: Long term trend of ocean surface normalized radar cross section observed by TRMM precipitation radar. Proc. Second Global Precipitation Mission (GPM) Int. Planning Workshop, Shinagawa, Japan, P11R. 9. [Available online at http://ams.confex. com/ams/pdfpapers/96443.pdf.]

Protat, A., and Coauthors, 2004: Le projet RALI: Combinaison d'un radar et d'un lidar pour l'étude des nuages faiblement précipitants. Météorologie, 47, 23-33. 
J. Delanoë, D. Bouniol, A. J. Heymsfield, A. Bansemer, and P. Brown, 2007: Evaluation of ice water content retrievals from cloud radar reflectivity and temperature using a large airborne in situ microphysical database. J. Appl. Meteor. Climatol., 46, 557-572.

$\longrightarrow,-$, A. Plana-Fattori, P. May, D. Bouniol, and E. O'Connor, 2009: The statistical properties of ice anvils and cirrus resulting from West African and Australian mesoscale convective systems. Quart. J. Roy. Meteor. Soc., in press.

Redelsperger, J.-L., and Coauthors, 2006: AMMA, une étude multidisciplinaire de la mousson ouest-africaine. Météorologie, 54, 22-32.

Rosenfeld, D., and W. L. Woodley, 2000: Deep convective clouds with sustained highly supercooled liquid water down to $-37.5^{\circ}$ C. Nature, $\mathbf{4 0 5}, 440-442$.

, - — T. W. Krauss, and V. Makitov, 2006: Aircraft microphysical documentation from cloud base to anvils of hailstorm feeder clouds in Argentina. J. Appl. Meteor. Climatol., 45, 1261-1281.

Stephens, G. L., and Coauthors, 2002: The Cloudsat mission and the A-train: A new dimension of space-based observations of clouds and precipitation. Bull. Amer. Meteor. Soc., 83, 1771-1790.

Stith, J. L., J. E. Dye, A. Bansemer, A. J. Heymsfield, C. A. Grainger, W. A. Petersen, and R. Cifelli, 2002: Microphysical observations of tropical clouds. J. Appl. Meteor., 41, 97-117.

Stokes, G. M., and S. E. Schwartz, 1994: The Atmospheric Radiation Measurement (ARM) Program: Programmatic back- ground and design of the Cloud and Radiation Test Bed. Bull. Amer. Meteor. Soc., 75, 1201-1221.

Tanelli, S., S. L. Durden, E. Im, K. S. Pak, D. G. Reinke, P. Partain, J. M. Haynes, and R. T. Marchand, 2008: Cloudsat's Cloud Profiling Radar after 2 years in orbit: Performance, external calibration, and processing. IEEE Trans. Geosci. Remote Sens., 46, 3560-3573.

Tinel, C., J. Testud, J. Pelon, R. J. Hogan, A. Protat, J. Delanoë, and D. Bouniol, 2005: The retrieval of ice-cloud properties from cloud radar and lidar synergy. J. Appl. Meteor., 44, 860-875.

Ulaby, F. T., R. K. Moore, and A. K. Fung, 1981: Microwave Remote Sensing Fundamentals and Radiometry, Vol. 1, Microwave Remote Sensing: Active and Passive, Artech House, $456 \mathrm{pp}$.

Wang, Z., and K. Sassen, 2002: Cirrus cloud microphysical property retrieval using lidar and radar measurements. Part I: Algorithm description and comparison with in situ data. J. Appl. Meteor., 41, 218-229.

Weinman, J. A., and M. J. Kim, 2007: A simple model of the millimeter-wave scattering parameters of randomly oriented aggregates of finite cylindrical ice hydrometeors. J. Atmos. Sci., 64, 634-644.

Wu, J., 1972: Sea-surface slope and equilibrium wind-wave spectra. Phys. Fluids, 15, 741-747.

— 1990: Mean square slopes of the wind distributed water surface, their magnitude, directionality and composition. Radio Sci., 25, 37-48. 